\title{
Modification of hypersonic waveriders by vorticity-based boundary layer displacement thickness determination method
}

\author{
Wen Liu ${ }^{a}$, Chen-An Zhang ${ }^{\mathrm{b}, *}$, Fa-Min Wang ${ }^{\mathrm{b}}$ \\ a Northwestern Polytechnical University, Xi'an 710072, People's Republic of China \\ b Institute of Mechanics, Chinese Academy of Sciences, Beijing 100190, People's Republic of China
}

\section{A R T I C L E I N F O}

\section{Article history:}

Received 27 September 2017

Received in revised form 11 December 2017

Accepted 12 December 2017

Available online 31 January 2018

\section{Keywords:}

Hypersonic waverider

Viscous interaction

Displacement thickness

Effective shape

Vorticity

\begin{abstract}
A B S T R A C T
For general hypersonic vehicles flying at high altitudes and Mach numbers, the appearance of the large boundary layer displacement thickness can change the pressure distribution and aerodynamic characteristics significantly. As for the waverider, another side effect is that the shock wave position is deflected downward evidently even at the design Mach number, which is adverse for the shock wave being attached to the leading edge and may lead to more leakage of high pressure gas from the lower surface onto the upper surface. Therefore, this paper first develops a vorticity-based method to determine the boundary layer displacement thickness, in combination with the tangent wedge/cone method. Then, trying to alleviate the high pressure gas leakage near the leading edge, modification of a viscous optimized waverider is conducted under the condition of strong viscous interaction, by deducting the corresponding boundary layer displacement thickness from the original lower surface along the normal direction. Results show that the shock wave position around the lower surface of the modified waverider under the condition of strong viscous interaction is very close to that of the inviscid basic flowfield around the original waverider, which means less leakage of high pressure gas. But it's found that such change has little influence on the aerodynamic characteristics of the upper surface. However, an interesting discovery is that due to the lower pressure near the leading edge of the modified lower surface, the wave drag is lowered for the same lift, thus the lift-to-drag ratio is improved. The modified waverider also exhibits higher lift-to-drag ratio at large angles of attack when compared to waveriders with upper expansion surfaces. Overall, a vorticity-based boundary layer displacement thickness determination method is proposed in this paper, which is then used to modify waveriders to achieve higher aerodynamic efficiency.
\end{abstract}

(c) 2018 Elsevier Masson SAS. All rights reserved.

\section{Introduction}

High lift-to-drag ratio $(L / D)$ is a key design objective for various kinds of hypersonic vehicles because higher $L / D$ means higher down \& cross range. For hypersonic flight characterized by large Mach numbers and high altitudes, the improvement of $L / D$ is especially difficult due to the severe wave drag and friction drag. Kuchemann put forward a general empirical correlation for the maximum $L / D$ based on data obtained from flight tests and experimental studies [1]:

$(L / D)_{\max }=\frac{4\left(M_{\infty}+3\right)}{M_{\infty}}$

\footnotetext{
* Corresponding author.

E-mail address: zhch_a@imech.ac.cn (C.-A. Zhang).
}

It shows that as the Mach number increases, an " $L / D$ barrier" exists for the traditional aircrafts. To break this barrier, a previous design concept of waverider proposed by Nonweiler [2], drew researchers' attention. An idealized waverider is carved from an inviscid basic flowfield. In this approach, the shock wave is attached to the leading edge of the waverider, thus preventing the spillage of high pressure gas from the lower surface onto the upper surface and achieving excellent aerodynamic efficiency. However, the earliest 'caret' waverider, generated from a planar wedge flowfield by Nonweiler, presented very limited 'volumetric' efficiencies and severe 'aerothermodynamic leading edge' that rendered them unrealistic at that time. Moore and Jones et al. [3,4] extended the planar flowfield to the axisymmetric conical flowfield. Such conederived waveriders present better volumes because the concave streamlines are closer to the shock wave [5]. Kim and Rasmussen et al. [6] applied the calculus of variations to yield the optimum cone-derived waveriders with maximum $L / D$ even when subjected to suitable engineering constraints. However, configurations opti- 


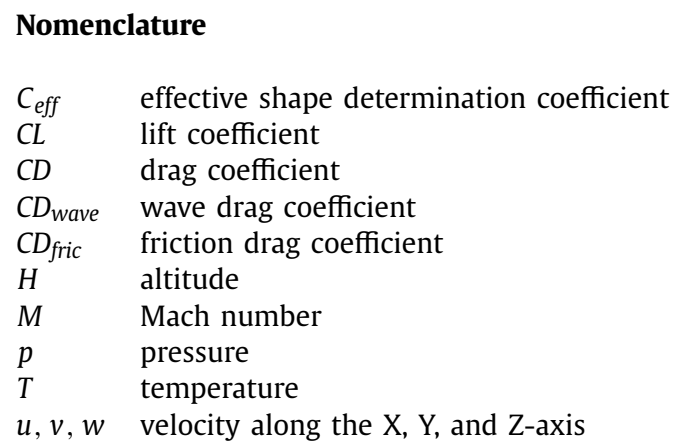

$\begin{array}{ll}\bar{V}^{\prime} & \text { viscous interaction parameter } \\ X c p & \text { relative location of the center of pressure } \\ \alpha & \text { angle of attack } \\ \gamma & \text { ratio of the specific heats, } 1.4 \\ \xi & \text { vorticity } \\ \delta^{*} & \text { boundary layer displacement thickness } \\ \beta & \text { shock wave angle } \\ \theta & \text { deflection angle of body surface relative to the } \\ \rho & \text { freestream direction } \\ \text { density }\end{array}$

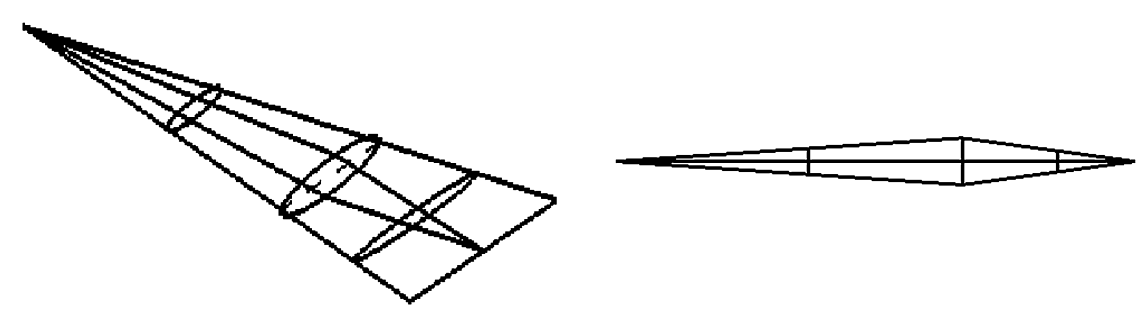

Fig. 1. All-body model

mized by inviscid analysis are likely to have very large wetted areas and massive friction drag [7]. Therefore, they may perform poorly when viscous effects are taken into account. The skepticism for the aerodynamic characteristics of waverider is eliminated by the concept of viscous optimized waverider proposed by Bowcutt, Corda and Anderson [8,9], where viscous effects were included for the first time during the optimization process. Then the effects of chemically reacting flow and viscous interaction were further included in the optimization process [10]. The viscous optimized waveriders were also the first hypersonic configurations to break the aforementioned " $L / D$ barrier". Since then, various kinds of waverider configurations are developed based on different basic flowfield [5,11-17]. A detailed overview of research on waverider design methodology is given by Ding et al. [18].

Potential application of waveriders for various hypersonic vehicles has also been widely discussed, including airbreathing hypersonic cruise vehicles [19], hypersonic entry vehicles [20], second stage for two-stage-to-orbit (TSTO) systems [21], and missions on other planets [22], etc. Before the application to realistic hypersonic vehicles, the waveriders must be studied thoroughly in various aspects, including off-design performance, aerothermal heating, stability and control, etc. For most researches, viscous effects are key factors that can seriously affect the theoretical performance of the waveriders. A number of problems may arise when viscous effects are taken into account, such as skinfriction drag, displaced shock, inviscid/viscous interaction in hypersonic regime [23]. Takashima studied a Mach 6 viscous optimized waverider by solving the three-dimensional Navier-Stokes (N-S) equations, demonstrating excellent on-design and off-design performance [24]. Viscous effects were also considered and studied by other literatures $[7,25,26]$. However, due to the relatively small Mach numbers, low altitudes and large waverider length-scale (30-60 m) focused on by most researchers, the viscous interaction is not strong enough to have an evident effect on the whole flowfield around the waverider. Under the condition of strong viscous interaction, the large boundary layer displacement thickness makes the effective shape differ from the original shape and changes the pressure distribution apparently [27]. Then a problem may be put forward: what effect will have on the aerodynamic characteristics of waverider by the obvious change of the effective shape? This paper tries to explore the above problem, in combination with a vorticity-based method to calculate the effective shape. Furthermore, an optimization method for the lower surface of waverider is presented based on boundary layer displacement thickness modification.

\section{Computational-fluid-dynamics code validation}

\subsection{Numerical methods}

An unstructured Computational-Fluid-Dynamics (CFD) solver GMFlow is used in this study [28]. A cell-centered finite volume method is employed to solve the three-dimensional compressible Euler or N-S equations. The AUSM+ spatial discretization scheme is adopted [29], with an implicit lower-upper symmetric GaussSeidel scheme for the temporal integration to accelerate convergence [30]. More details about the CFD solver can be found in [28, 31].

\subsection{Validation}

The experimental results of an all-body hypersonic aircraft model from [32] are used to validate the accuracy of the current CFD code. The model is shown in Fig. 1. The test conditions include: $M_{\infty}=7.4, \operatorname{Re}_{\infty, L}=15 \times 10^{6}(L=0.9144 \mathrm{~m})$, $\alpha=0,5,10,15 \mathrm{deg}, T_{\infty}=62 \mathrm{~K}$ and $T_{w}=300 \mathrm{~K}$. The 3-equation $k-\varepsilon-R t$ turbulence model is adopted in the computations [33]. The effects of angle of attack on the windward and leeward centerline pressures are summarized in Fig. 2. For the windward side, good agreement is achieved between the pressures by the experiment and by the CFD code. The forebody pressures are slightly underpredicted at higher angles of attack, which is similar to those from the NASA Ames UPS code [32]. For the leeward side, good agreement is also obtained between the experimental and numerical results. The above results show that the current CFD code is reliable for the calculation of hypersonic aerodynamic problems.

\section{Vorticity-based effective shape determination method}

It's well known that for hypersonic flight, the high altitudes and large Mach numbers may lead to a thick hypersonic boundary layer, which displaces the outer inviscid flow and changes the 


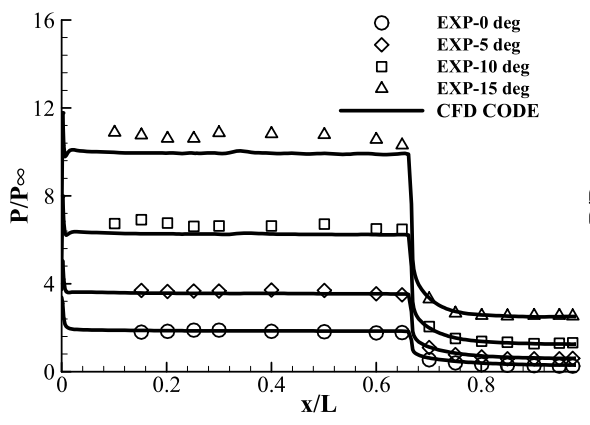

a) Windward

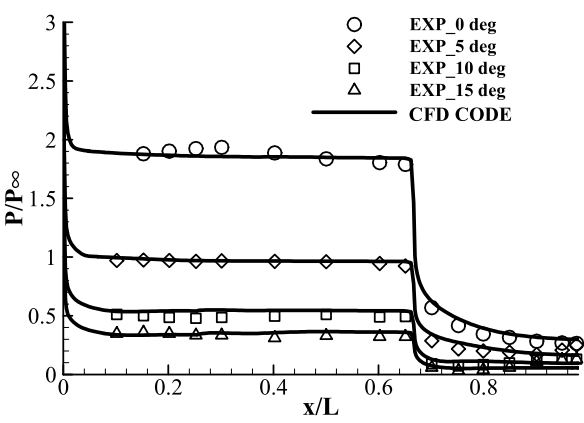

b) Leeward

Fig. 2. Pressure distribution along the centerline from the experimental and CFD results.

nature of the inviscid flow. In turn, the substantial changes on the outer inviscid flow may feedback to the boundary layer, affecting its growth and properties. Such mutual interaction process is called a strong viscous interaction [27], whose influence on the aerodynamic characteristics of hypersonic vehicles can be captured by the concept of effective shape, namely the original body plus the boundary layer displacement thickness. According to the relationship between vorticity and viscous flow, a vorticity-based semiempirical correlation to determine the average effective shapes of moving airfoils was proposed in [34]. Here, the idea is further developed in combination with the tangent wedge/cone method to obtain the effective shapes of hypersonic thin bodies in the steady flight condition.

\subsection{Derivation of vorticity-based effective shape determination method}

Generally speaking, the flow is highly rotational with high vorticity inside the boundary layer and lowly rotational with low vorticity outside the boundary layer. Therefore, vorticity can be used to distinguish the viscous flow from the inviscid flow, thus determining the effective shape.

Vorticity is defined as:

$$
\begin{aligned}
\boldsymbol{\xi} & =\nabla \times \mathbf{V} \\
& =\left(\frac{\partial w}{\partial y}-\frac{\partial v}{\partial z}\right) \vec{i}+\left(\frac{\partial u}{\partial z}-\frac{\partial w}{\partial x}\right) \vec{j}+\left(\frac{\partial v}{\partial x}-\frac{\partial u}{\partial y}\right) \vec{k}
\end{aligned}
$$

The flat plate laminar boundary-layer displacement thickness equation by Anderson [27] for strong inviscid-viscous interaction case is:

$\delta^{*} \propto M^{1 / 2} \operatorname{Re}^{-1 / 4} x^{3 / 4}$

where $R e$ is the unit Reynolds number, $M$ is the Mach number, and $x$ is the distance offset from a point on the body surface to the leading edge in the longitudinal plane. Assuming that the normal gradient of the streamwise velocity is much larger than the gradient of the other directions, which is reasonable for most flows around slender hypersonic configurations, we can get the following criterion to obtain the effective shape:

$|\xi|<C_{e f f} \frac{u}{M^{1 / 2} R e^{-1 / 4} \chi^{3 / 4}}$

where $C_{\text {eff }}$ is the effective shape determination coefficient and includes the possible factors that affect the effective shape. The right side of Equation (3) represents an approximate expression of the average vorticity inside the boundary layer. According to the flowfield from the steady $\mathrm{N}-\mathrm{S}$ solutions, vorticity of each grid point is searched from the body surface to the outside flowfield along the normal direction. Then at the position where vorticity satisfies Equation (3) firstly, the edge of effective shape is determined, along with the local flow quantities at the edge of the boundary layer. Note that at each step, the local flow quantities are substituted into the right side of Equation (3). Therefore, the flow quantities $\operatorname{Re}, M$ and $u$ are finally based on the local flow quantities at the edge of the boundary layer.

The viscous interaction effect has a major influence on the boundary layer displacement thickness and viscous interaction parameters denote the strength of viscous interaction. Therefore, a correlation may exist between the effective shape determination coefficient $C_{\text {eff }}$ and the viscous interaction parameter. The viscous interaction parameter $\bar{V}^{\prime}$ is adopted and defined as [27]:

$\bar{V}^{\prime}=\frac{M_{\infty} \sqrt{C^{\prime}}}{\sqrt{\operatorname{Re}_{\infty, L}}}$

where

$C^{\prime}=\frac{\rho^{\prime} \mu^{\prime}}{\rho_{\infty} \mu_{\infty}}$

where $\rho^{\prime}$ and $\mu^{\prime}$ are evaluated at the reference temperature $T^{\prime}$ within the boundary layer, and the reference length $L$ equals the chord length in the longitudinal plane. A reference temperature method suggested by Anderson is employed here [35]:

$T^{\prime} / T_{\infty}=1.28+0.023 M_{\infty}^{2}+0.58\left(T_{w} / T_{\infty}-1\right)$

The viscosity coefficient $\mu^{\prime}$ is calculated by the Sutherland law:

$\frac{\mu^{\prime}}{\mu_{0}}=\left(\frac{T^{\prime}}{T_{0}}\right)^{\frac{3}{2}} \frac{T_{0}+110.4}{T^{\prime}+110.4}$

where $\mu_{0}=1.716 \times 10^{-5} \mathrm{~kg} /(\mathrm{ms}), T_{0}=273.11 \mathrm{~K}$ and the wall temperature $T_{w}=1000 \mathrm{~K}$. Through Equation (4) to (7), the viscous interaction parameter $\bar{V}^{\prime}$ is determined at a given flight condition.

In order to find the relation between $C_{\text {eff }}$ and $\bar{V}^{\prime}$, a series of steady $\mathrm{N}-\mathrm{S}$ numerical simulations for a two-dimensional semiwedge, with the semi-wedge angle being $6.33 \mathrm{deg}$ and the length being $4 \mathrm{~m}$, are conducted at zero angle of attack with different $\bar{V}^{\prime}$. The geometrical parameter of the semi-wedge is chosen for that it has the same length and height in the base plane as the symmetry section plane of the original waverider used in this paper. The laminar boundary layer is assumed in the CFD computations because of the large Mach number and small Reynolds number. In addition, an isothermal wall condition with $T_{w}=1000 \mathrm{~K}$ is employed. And the paper adopts the perfect gas model, neglecting the real gas effect. Then the upper surface of the semi-wedge, which is a flat plate, is used to determine the relation between $C_{\text {eff }}$ and $\bar{V}^{\prime}$. The lower surface can be used to validate the accuracy of the flat plate 


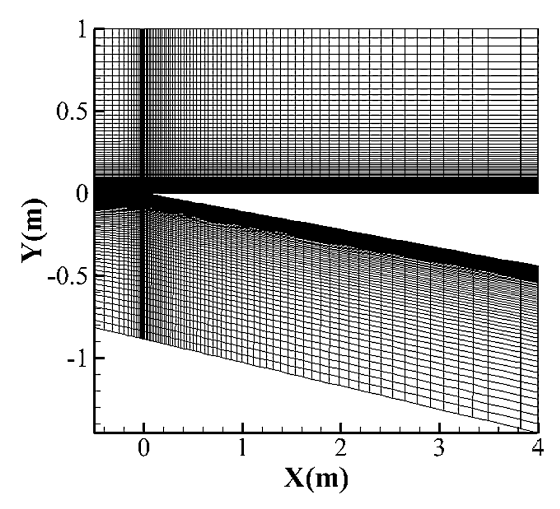

Fig. 3. Grid around the two-dimensional semi-wedge.

displacement thickness determination criterion when applying to the general thin bodies.

The grid around the semi-wedge is shown in Fig. 3. To determine the boundary layer edge as accurately as possible, the grid nodes adjacent to the wall are refined, with the height of the firstlayer grid nodes away from the wall being $1 \mathrm{E}-4 \mathrm{~m}$. And there are 65 grid nodes along the streamwise direction and 101 grid nodes along the normal direction. The growth rates of the space between neighboring grid nodes are 1.1 and 1.05 , respectively.

The tangent-wedge (TW) method is employed here to help determine the effective shape because the accuracy of this approximate method is usually surprisingly high when applied to the hypersonic aerodynamic forces prediction for simple twodimensional (2D) thin bodies. For three-dimensional (3D) bodies, the TW method is replaced by the tangent cone (TC) method.

For the TW method, the formula can be written as:

$\frac{p_{e}}{p_{\infty}}=1+\frac{\gamma(\gamma+1)}{4} K^{2}+\gamma K^{2} \sqrt{\left(\frac{\gamma+1}{4}\right)^{2}+\frac{1}{K^{2}}}$

For the TC method, the formula is:

$\frac{p_{e}}{p_{\infty}}=1+\frac{\gamma M_{\infty}^{2}}{2} \cdot \frac{4 \sin ^{2} \theta(2.5+8 K)}{1+16 K}$

where $K=M_{\infty} \theta$.

For a given value of $C_{e f f}$, an effective shape can be determined according to the process described above. The grid nodes on the effective shape are smoothed with a linear least square fitting using the following equation:

$Y=c_{1} X^{0.25}+c_{2} X^{0.5}+c_{3} X^{0.75}+c_{4} X+c_{5} X^{1.25}+c_{6} X^{1.5}$

The TW method is used here to calculate the pressure distribution of the effective shape, which is then projected onto the original body. Furthermore, the error between the pressure distribution on the original body from the effective-shape-based TW (ES-TW) result and CFD result is evaluated. The error is defined as:

Error $=\sum_{i=1}^{n}\left(P_{C F D}-P_{T W}\right)^{2}$

where $n$ corresponds to the number of total grid nodes on the body.

For each case, vary $C_{\text {eff }}$ until the error in Equation (11) is minimized. Then the final boundary layer displacement thickness, or the effective shape, is determined. The corresponding flight conditions and final results are listed in Table 1 . The boundary layer displacement thickness and the comparison of pressure distribution at several flight conditions are plotted in Fig. 4 and Fig. 5,
Table 1

Conditions for $C_{e f f}$ determination.

\begin{tabular}{llll}
\hline$M_{\infty}$ & $H / \mathrm{km}$ & $\bar{V}^{\prime} \times 10^{-2}$ & $C_{\text {eff }}$ \\
\hline 10 & 40 & 0.427 & 0.787 \\
10 & 45 & 0.613 & 0.904 \\
15 & 50 & 0.945 & 1.056 \\
15 & 55 & 1.267 & 1.210 \\
15 & 60 & 1.707 & 1.381 \\
\hline
\end{tabular}

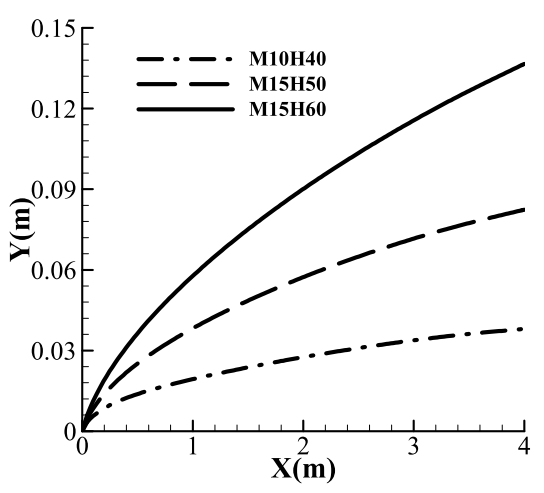

Fig. 4. Flat plate boundary layer displacement thickness.

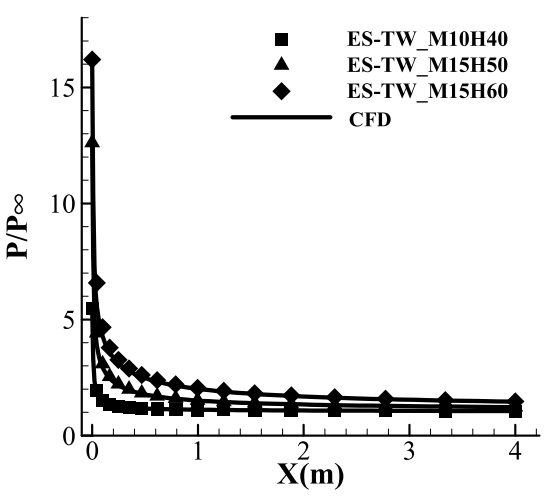

Fig. 5. Comparison of pressure distribution.

respectively. Excellent agreement between the pressure distribution from CFD results and effective-shape-based TW results is obtained. The vorticity distribution along the normal direction, both inside and outside the boundary layer, is plotted in Fig. 6 at several $\mathrm{X}$-axis positions. Obviously, the value of vorticity inside the boundary layer is much larger than that outside the boundary layer. In addition, the value of vorticity at the edge of the boundary layer gradually decreases along the streamwise direction.

Interestingly, a nearly linear relation between $C_{\text {eff }}$ and $\sqrt{\bar{V}^{\prime}}$ is found, shown in Fig. 7. Therefore, the expression for $C_{\text {eff }}$ as a function of $\sqrt{\bar{V}^{\prime}}$ can be determined through linear fitting:

$C_{\text {eff }}=9.05 \sqrt{\bar{V}^{\prime}}+0.19$

Then Equation (3) can be rewritten as:

$|\xi|<\left(9.05 \sqrt{\bar{V}^{\prime}}+0.19\right) \cdot \frac{u}{M^{1 / 2} R e^{-1 / 4} \chi^{3 / 4}}$

\subsection{Discussion about the application}

The lower surface of the semi-wedge is used to validate the accuracy of the method when applying to general hypersonic thin bodies. The inviscid aerodynamic forces, including the lift coefficients, drag coefficients and the relative position of center of pres- 


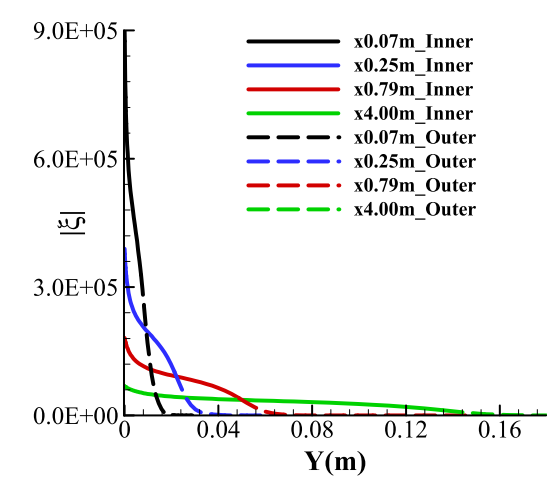

Fig. 6. Vorticity distribution along the normal direction.

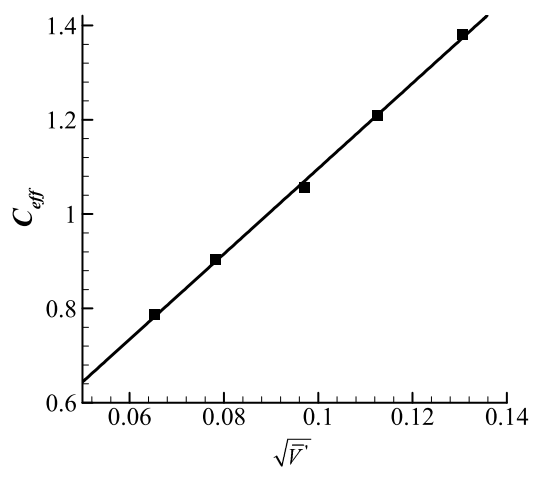

Fig. 7. Linear fitting of $C_{e f f}$ with $\sqrt{\bar{V}^{\prime}}$.

Table 2

Relative errors of inviscid aerodynamic forces.

\begin{tabular}{lllll}
\hline$M_{\infty}$ & $H / \mathrm{km}$ & \multicolumn{4}{l}{ Relative error (\%) } \\
\cline { 3 - 5 } & & $C L$ & $C D$ & $X c p$ \\
\hline 10 & 40 & 1.87 & 1.87 & 0.84 \\
10 & 45 & 2.55 & 2.55 & 1.26 \\
15 & 50 & 4.31 & 4.31 & 1.20 \\
15 & 55 & 4.29 & 4.29 & 1.59 \\
15 & 60 & 4.24 & 4.24 & 0.91 \\
\hline
\end{tabular}

sure $(X c p)$, calculated from the effective-shape-based TW method are compared with those from the CFD results. The relative errors are listed in Table 2 . The maximum error is only $4.31 \%$, which demonstrates indirectly that the vorticity-based effective shape determination criterion according to the flat plate is valid for general hypersonic thin bodies.

However, if we want to obtain a more accurate effective shape for a general thin body, the process of the above derivation for the flat plate can be used for reference. Namely, for a specified thin body, vary the value of $C_{e f f}$ until the error of pressure distribution in Equation (11) is minimized. The comparison of the effective shape and pressure distribution for the lower surface of the semiwedge at $H=60 \mathrm{~km}$ are shown in Fig. 8 and Fig. 9, respectively, where "ES2" represents the second effective shape, or the one obtained according to the optimum value of $C_{\text {eff }}$. The two effective shapes are very close. It's also shown that, compared to the CFD result, good agreement of the pressure distribution is achieved from both of the two effective shapes, while the pressure distribution calculated from the second effective shape is a little closer to the CFD result.

Therefore, based on the above analysis, for a rapid prediction of the effective shapes of general hypersonic thin bodies, the criterion from Equation (13) is suggested. If a more accurate effective shape is desired, the optimum value of $C_{\text {eff }}$ should be found for a

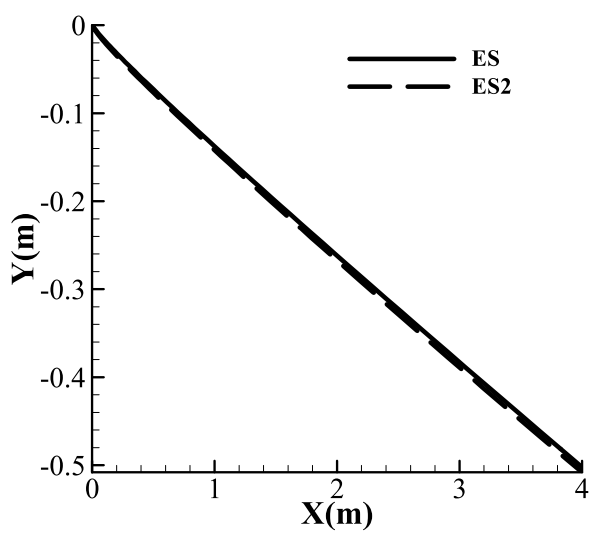

Fig. 8. Comparison of the effective shape.

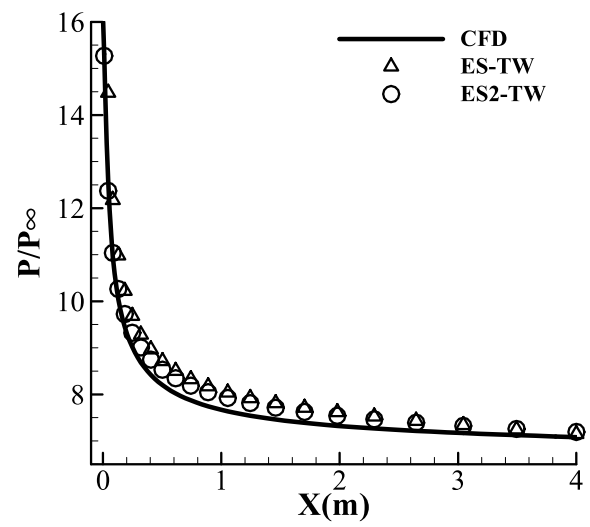

Fig. 9. Comparison of the pressure distribution.

specified thin body. The process for obtaining the effective shape is summarized in Fig. 10.

\section{Strong viscous interaction effects}

A typical viscous optimized cone-derived waverider is adopted as the research object in this paper. Then the influences of strong viscous interaction on the performance of the waverider are analyzed in detail in this section.

\subsection{Viscous optimized waverider}

Referring to the idea of Bowcutt [8], a viscous optimized conederived waverider can be generated. The inviscid conical flow is calculated from the Taylor-Maccoll equations, using a fourthorder Runge-Kutta numerical technique. Accordingly, the inviscid pressure of the waverider's lower surface can be obtained. The freestream surface is adopted as the upper surface and the pressure is freestream pressure, $P_{\infty}$. In addition, the base pressure is also approximately equal to freestream pressure.

Viscous effects are calculated by Eckert's reference temperature method [35]. For the laminar flow, the local skin friction is evaluated as:

$c_{f, \text { Lam }}^{\prime}=\frac{0.664}{\sqrt{R e_{x}^{\prime}}}$

where the Reynolds number is defined as:

$\operatorname{Re}_{x}^{\prime}=\frac{\rho^{\prime} u_{e} x}{\mu^{\prime}}$ 


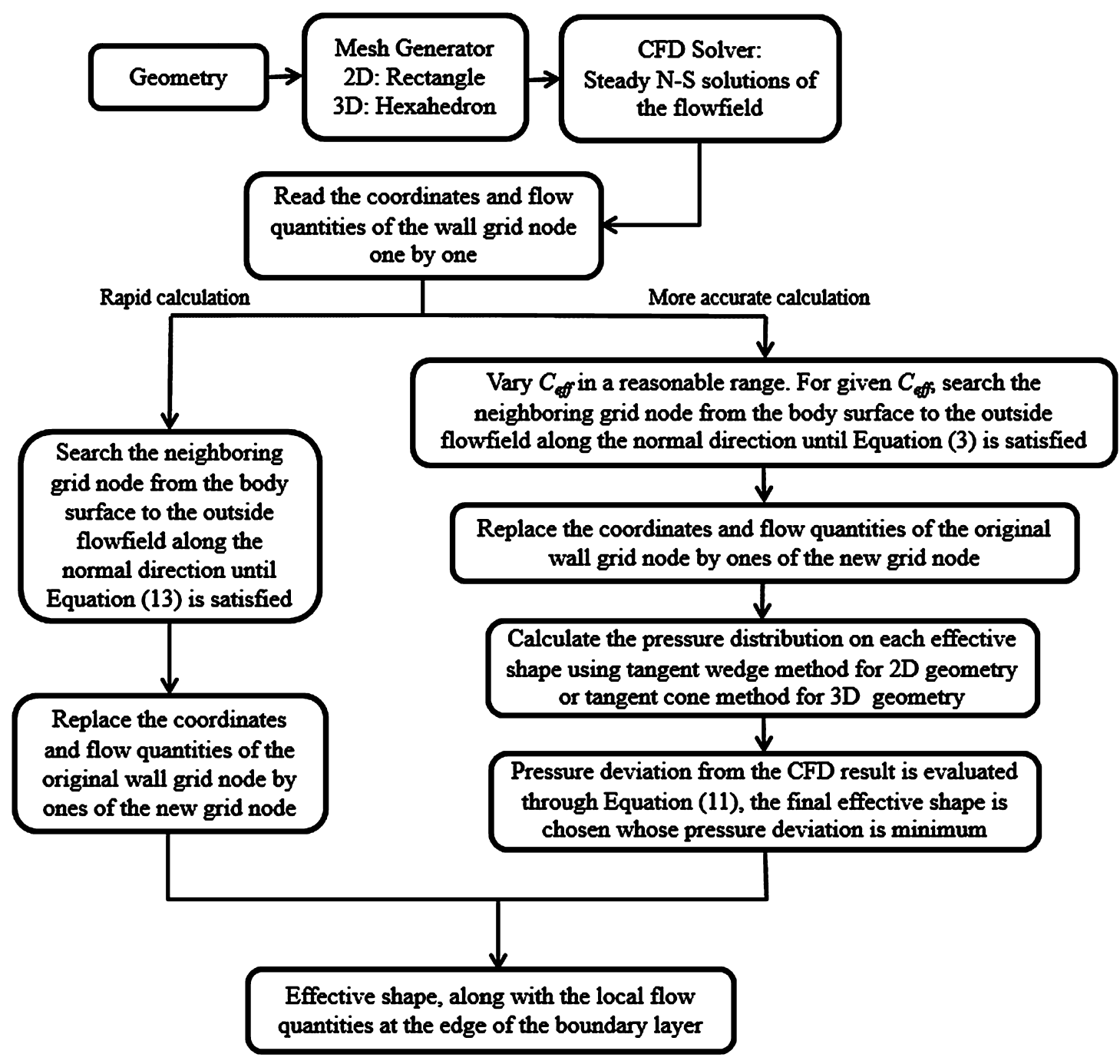

Fig. 10. Flow chart for obtaining the effective shape.

where $\rho^{\prime}=P_{\infty} / R T^{\prime}$ and $T^{\prime}$ is calculated by Equation (6). For turbulent flow, the local skin friction is evaluated as:

$c_{f, T u r}^{\prime}=\frac{0.074}{\left(R e_{x}^{\prime}\right)^{0.2}}$

The prediction and handling of the transition region is the same as the method used by Bowcutt [8], thus it is not introduced here.

The waverider is determined by the base curve on the base plane, shown in Fig. 11. A cubic spline-fit through five control points is used to generate a continuous base curve on one half and the curve is mirrored to the other half. Given a group of initial base curves, the simplex method by Nelder and Mead [36] is employed to obtain the optimum waverider with the maximum $L / D$. Note that the length of the generating shock wave along X-axis is chosen to be 1 and the radius of the shock wave on the base plane is calculated according to the shock wave angle $\beta$. Then the created waverider is scaled up to the required length.

The current design condition is specified as: $M_{\infty}=15, H=$ $60 \mathrm{~km}, \beta=8.5 \mathrm{deg}, L=4 \mathrm{~m}$. The generated viscous optimized waverider is shown in Fig. 12 . The base curve on the left half $(Z \geq 0)$, defined on the shock wave circle with a radius of 0.149 , can be expressed as the following third-order polynomial:

$Y=-0.0687-6.36 Z^{2}+24.12 Z^{3}$

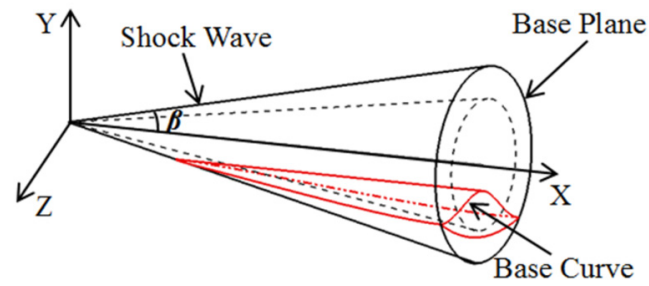

Fig. 11. Generation of cone-derived waverider.

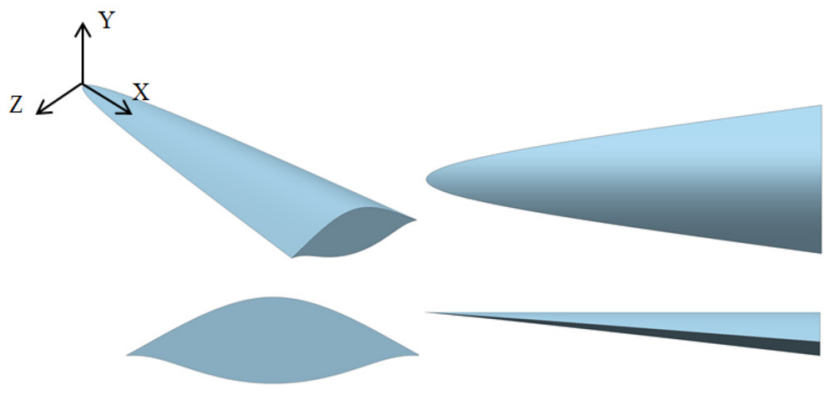

Fig. 12. Viscous optimized waverider. 


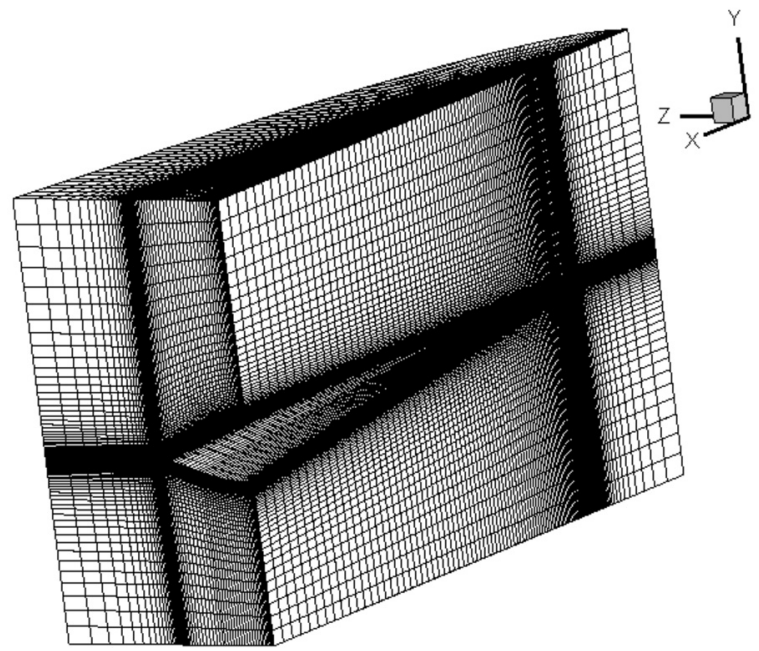

Fig. 13. Half-symmetric grid used in CFD simulations (approximately 600,000 cells).

Table 3

Comparison of force coefficients at the condition: $M_{\infty}=15, H=60 \mathrm{~km}, \alpha=0 \mathrm{deg}$.

\begin{tabular}{lll}
\hline Grid & Coarser grid & Finer grid \\
\hline$C L$ & $2.910 \mathrm{E}-2$ & $2.914 \mathrm{E}-2$ \\
$C D_{\text {wave }}$ & $3.771 \mathrm{E}-3$ & $3.774 \mathrm{E}-3$ \\
$C D_{\text {fric }}$ & $7.557 \mathrm{E}-3$ & $7.565 \mathrm{E}-3$ \\
\hline
\end{tabular}

\subsection{Grid generation}

The half-symmetric grid, with approximately 600,000 cells, is generated due to symmetry of the waverider, shown in Fig. 13. At the condition of $M_{\infty}=15, H=60 \mathrm{~km}$, the dimensionless distance of the first-layer grid nodes away from the body surface in the normal direction is $1 \mathrm{E}-4$. A grid-sensitivity study is also conducted using a grid with approximately 1,200,000 cells, refined along the streamwise direction on the body. The corresponding force coefficients are listed in Table 3. The reference area of the half-model is $1.828 \mathrm{~m}^{2}$, being equal to the projected area toward $\mathrm{X}-\mathrm{Z}$ plane. The base region is not included in the CFD analysis and the base pressure is set to be the freestream pressure. And the laminar flow model is employed. We can see from Table 3 that the results from two grids are extremely identical. Therefore, the coarser grid is used herein to save the computational resources and time.

\subsection{Aerodynamic performance from numerical results}

At the condition $M_{\infty}=15$, the Euler solutions and N-S solutions at the altitudes of $40 \mathrm{~km}, 50 \mathrm{~km}$, and $60 \mathrm{~km}$ are obtained through CFD simulation for the viscous optimized waverider. Then the effective shapes at different altitudes can be acquired by applying the rapid method introduced in Section 3 to aid in qualitative analysis. The influences of strong viscous interaction on lift and drag coefficients of the lower surface and upper surface are analyzed alone, which finally explains the variation trend of the inviscid $L / D$ (not including the shear stresses) of the waverider at different altitudes.

Fig. 14 shows the comparison of the original waverider and effective shapes at different altitudes at $\alpha=0 \mathrm{deg}$. At higher altitudes, the viscous interaction effects are stronger, thus the effective shape becomes thicker. The stronger compression effect over the lower surface makes the Mach number lower and density larger behind the shock wave, which weakens the viscous interaction effects. Hence, the effective shape of the upper surface is thicker than that of the lower surface at the same altitude. The different compression and expansion effect can also explain the variation

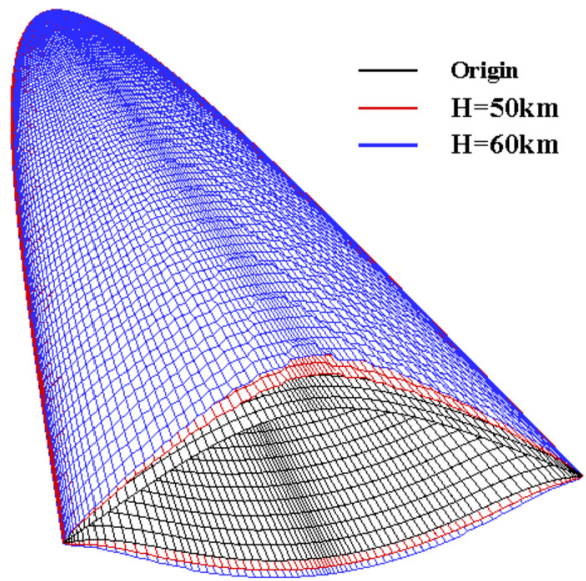

Fig. 14. Effective shapes at different altitudes.

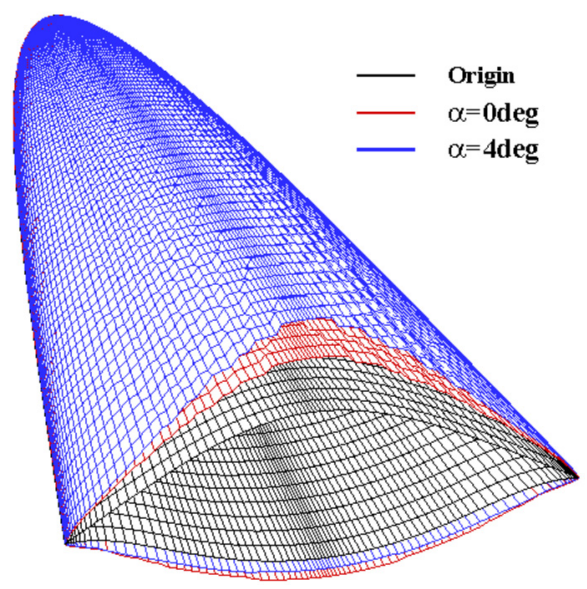

Fig. 15. Effective shapes at different angles of attack.

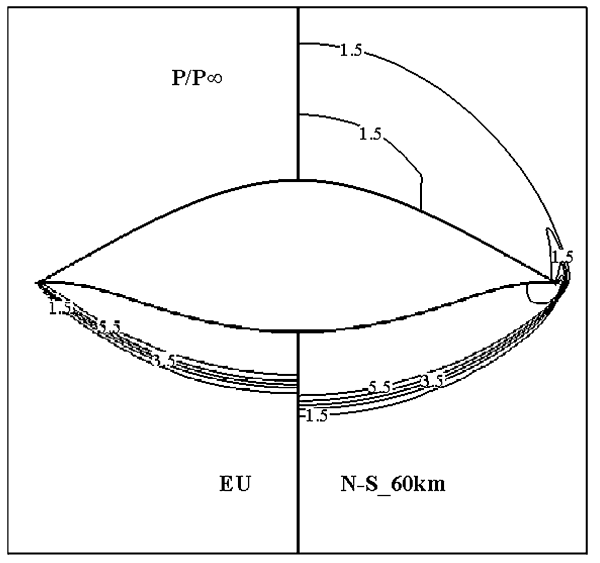

Fig. 16. Pressure contour at the base plane.

trend of the effective shape with angle of attack at $H=60 \mathrm{~km}$, depicted in Fig. 15, which shows that increasing angle of attack makes the effective shape thinner for the lower surface and thicker for the upper surface.

Fig. 16 shows the pressure contour at the base plane. It shows that at the design Mach number, the shock wave location at $H=$ $60 \mathrm{~km}$ is deflected downward evidently from that of Euler result owing to the thick boundary layer displacement thickness. Furthermore, the pressure distribution along the centerline is shown in Fig. 17. Obviously, the pressure increase is more severe as the alti- 
tude increases, especially near the leading edge where the viscous interaction effects are strong. The difference gradually decreases toward the end of the centerline because the viscous interaction effects become weaker and weaker.

Fig. 18 shows the comparison of force coefficients at different angles of attack for the four calculation cases, including $C L, C D$, $C D_{\text {wave }}$ and $C D_{\text {fric }}$. To see more clearly, the lift and drag coefficients of only $0-2$ deg angles of attack are plotted. As the altitude increases, the major change is the increase in the friction drag, mainly caused by the decrease of the Reynolds number. Besides, the wave drag is also increased due to the thicker effective shape of the lower surface at higher altitudes. As the angle of attack in-

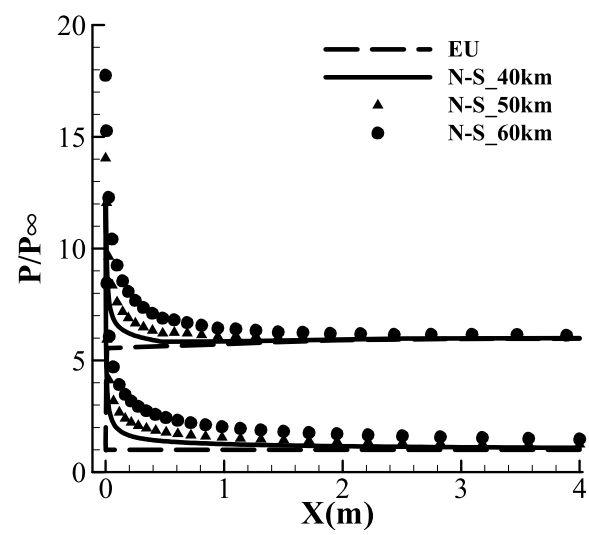

Fig. 17. Pressure distribution along the centerline at different altitudes, $\alpha=0 \mathrm{deg}$.

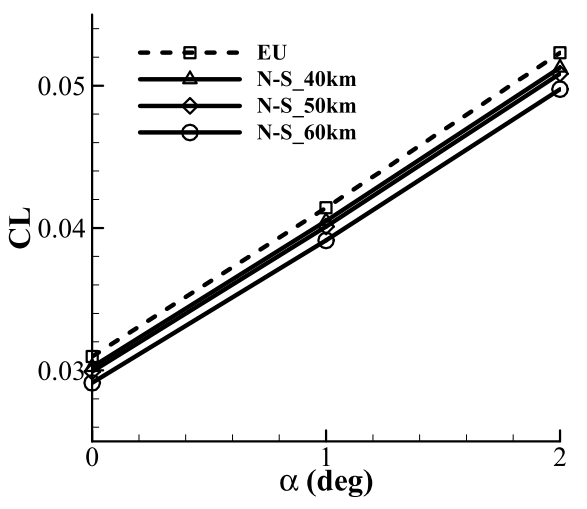

a) Lift coefficient

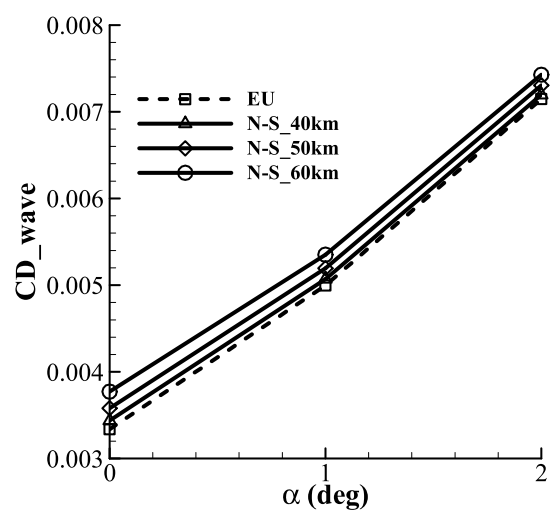

c) Wave drag coefficient creases, the effective shape of the lower surface is closer to the original surface, shown in Fig. 15. In turn, the difference of wave drag under the four different conditions is lowered at higher angles of attack. Note that the contribution to the wave drag by the upper surface is negligible. Compared to the Euler result, the lift coefficients under the condition of strong viscous interaction are reduced. This result can be explained by Fig. 19, where the force contribution of the upper surface and lower surface to the total lift is shown. As the altitude increases, the lift of the lower surface and the negative lift of the upper surface both increase. However, the variation is larger for the upper surface. One reason should be the stronger viscous interaction effects of the upper surface. The other reason may be due to the more severe leakage of high pressure gas from the lower surface onto the upper surface at higher altitudes, which will be analyzed in the next section.

Finally, the values of inviscid $L / D$ of the lower surface and the total waverider are plotted in Fig. 20. It can be seen that although the strong viscous interaction has an evident influence on the lift and drag coefficients, its influence on the inviscid $L / D$ of the lower surface can be neglected. Furthermore, at small angles of attack ( $\alpha \leq 4 \mathrm{deg}$ ), the inviscid $L / D$ of the total waverider decreases as the viscous interaction effects become stronger, mainly because of the negative lift produced by the upper surface as analyzed above. At larger angles of attack, it can be easily deduced that the force on the lower surface plays a dominant role in the inviscid $L / D$ of the waverider and thus almost not affected by the viscous interaction effects.

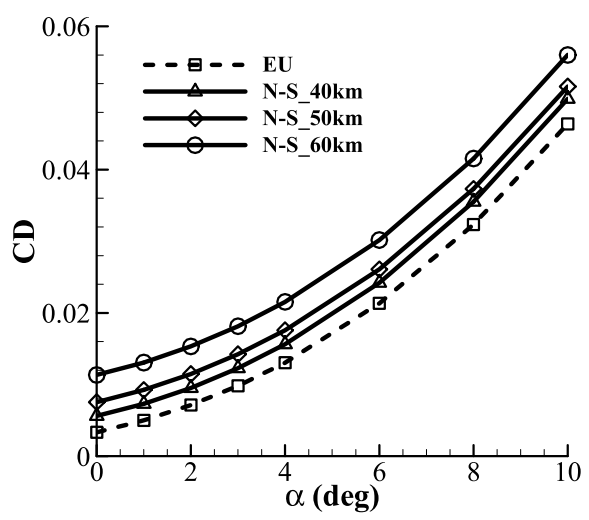

b) Drag coefficient

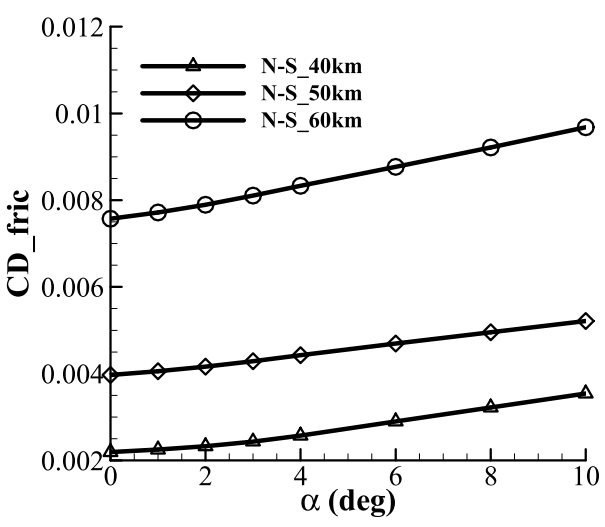

d) Friction drag coefficient

Fig. 18. Force coefficients from Euler result and N-S results at different altitudes. 


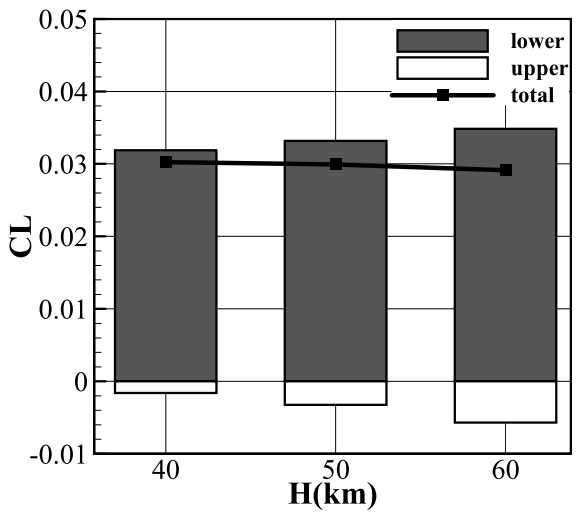

Fig. 19. Force contribution to the total lift coefficient, $\alpha=0$ deg.

\section{Boundary layer modification to the waverider}

The above analysis shows that the pressure increase on the upper surface is the main reason that lowers the inviscid $L / D$ of the waverider, which may be partly attributed to the leakage of high pressure gas from the lower surface onto the upper surface. For a real hypersonic waverider vehicle, such gas leakage near the leading edge is inevitable due to viscous effects, especially considering the fact that the leading edge must be blunted. However, under the strong viscous interaction condition, the downward deflection of the shock wave, shown in Fig. 16, is likely to further aggravate the leakage effect, which was not considered in past researches. Therefore, in an attempt to alleviate the leakage near the leading edge caused by the change of the shock wave position, a modification method is first proposed here by deducting the displacement thickness from the lower surface of original waverider, namely, letting the shock wave around the effective shape approach that of the inviscid basic flowfield. The design condition is: $M_{\infty}=15$, $H=60 \mathrm{~km}, \alpha=0 \mathrm{deg}$.

\subsection{Geometry generation}

In order to obtain an accurate boundary layer displacement thickness, the optimum value of $C_{\text {eff }}=2.3317$ is found in combination with the tangent cone method. With each streamline of the lower surface deducted by the corresponding displacement thickness along the normal direction, a modified waverider can be generated. The comparison of the profile between the original and modified waverider is shown in Fig. 21.

It should be noted that the displacement thickness of the lower surface between the modified and the original waverider is a little different due to the slightly different compression effect. Fig. 22

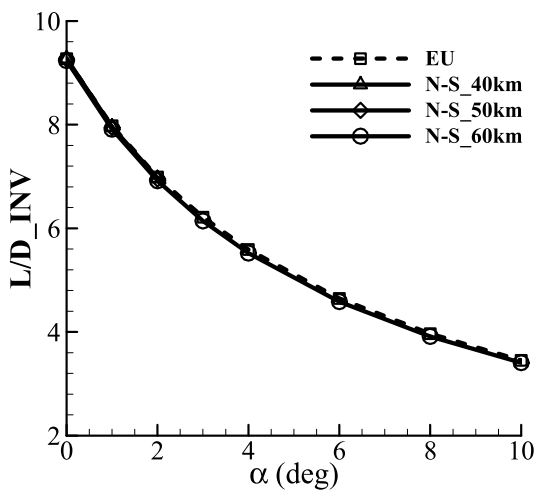

a) Lower surface shows the comparison of the effective shape of the modified waverider, from the optimum $C_{e f f}$, and the original waverider at different cross sections. The two profiles are very close, which shows that the displacement thickness is not changed evidently by the minor difference of the lower surface.

\subsection{Shock wave position}

Fig. 23 shows the comparison of the pressure contour at different cross sections. Obviously, the shock wave position of the modified waverider under strong viscous interaction condition is very close to that of the inviscid design condition, which also demonstrates the reasonable accuracy of the boundary layer displacement thickness calculated in this paper.

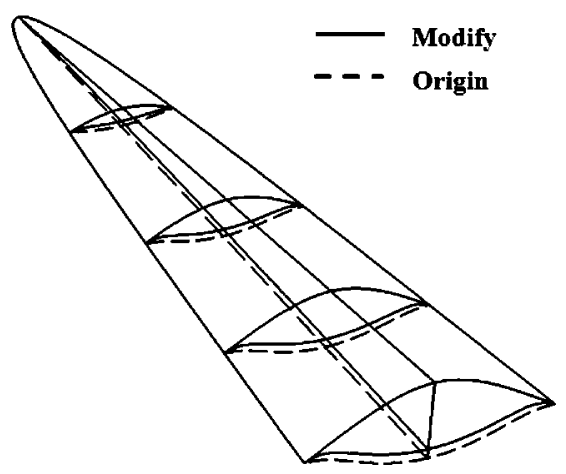

Fig. 21. Profile of the original modified waverider.

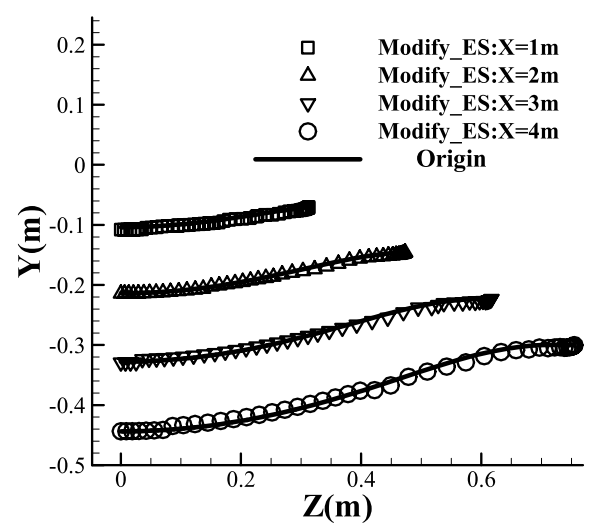

Fig. 22. Comparison of lower surface between the original waverider and the effective shape of the modified waverider.

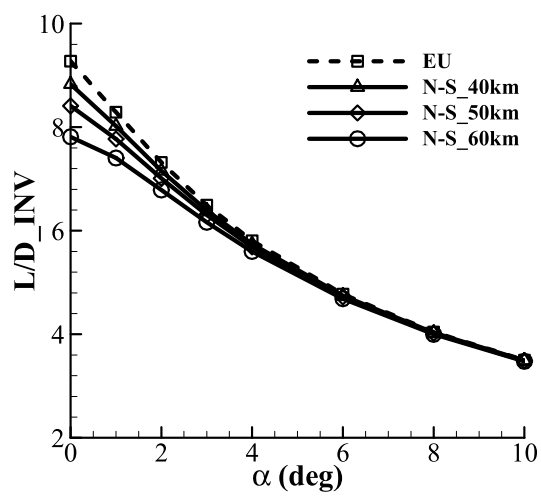

b) Total waverider

Fig. 20. Inviscid $L / D$ from Euler result and $\mathrm{N}-\mathrm{S}$ results at different altitudes. 


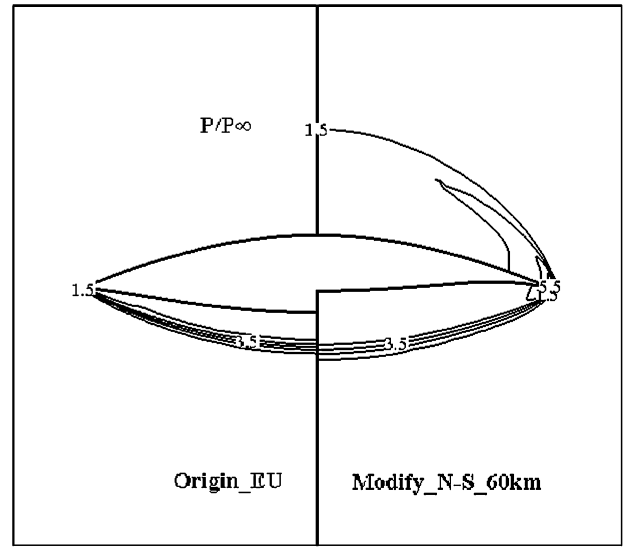

a) $X=1 m$

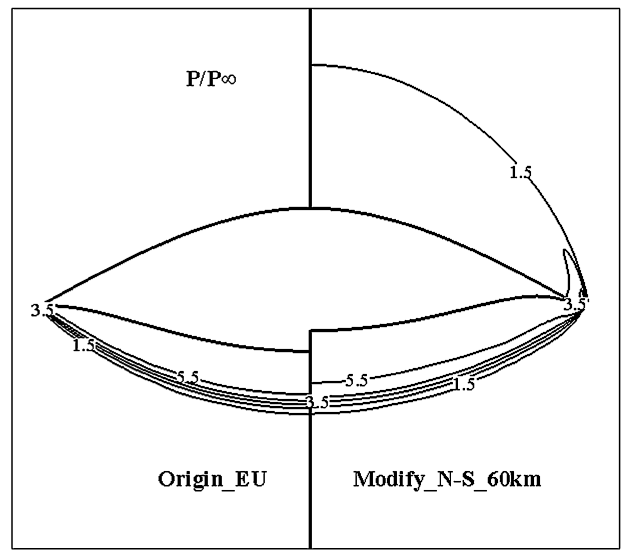

c) $X=3 m$

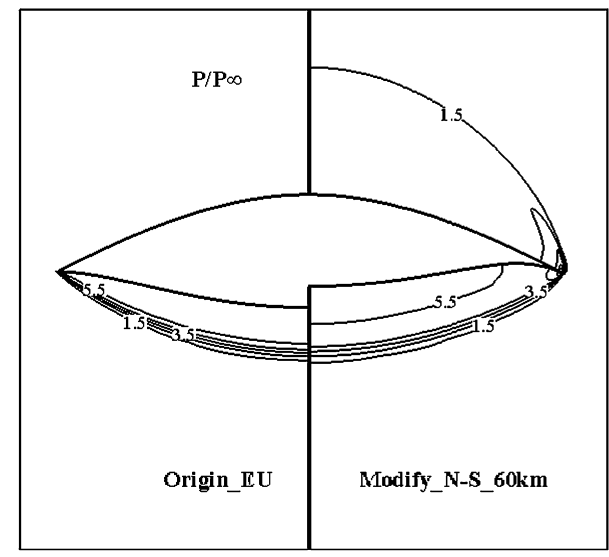

b) $X=2 m$

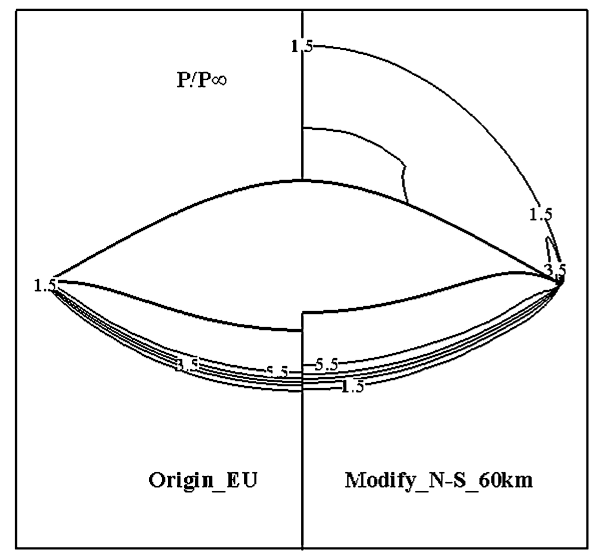

d) Base plane

Fig. 23. Comparison of pressure contour at different cross sections.

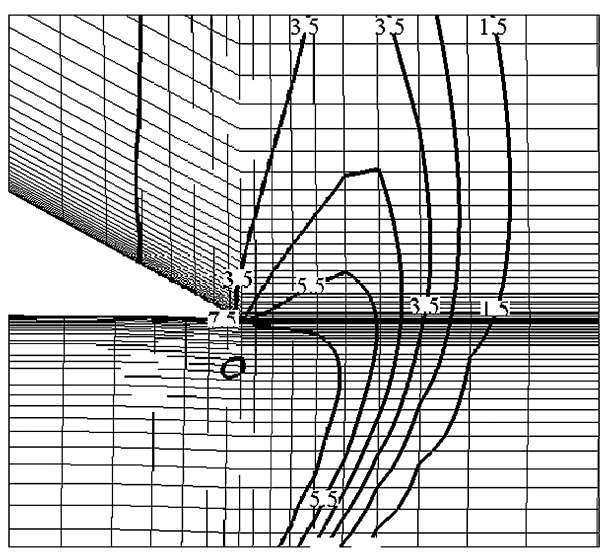

a) Original waverider

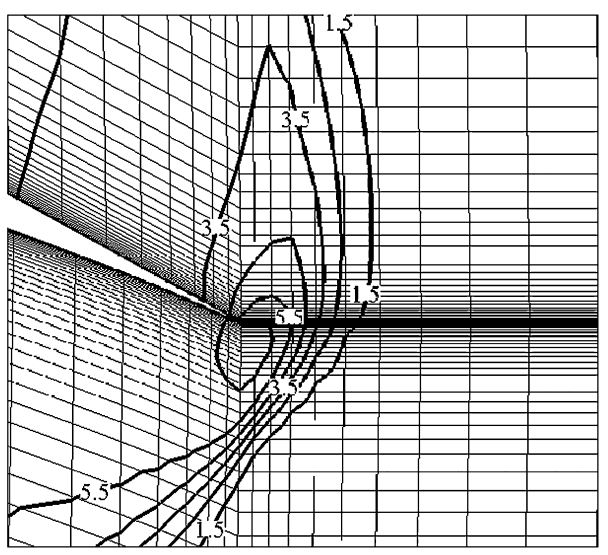

b) Modified waverider

Fig. 24. Comparison of pressure contour $\left(P / P_{\infty}\right)$ from N-S results near the leading edge at the base plane.

Fig. 24 shows the comparison of the pressure contour at the base plane near the leading edge. As expected, the shock wave around the modified waverider lies closer to the leading edge, which generally means less leakage of high pressure gas. However, it's found that such improvement of the shock wave position has little influence on the lift of the upper surface. Therefore, it can be inferred that the lift variation of the upper surface with altitude is mainly dominated by a direct influence of strong viscous interac- tion effects, not the leakage of high pressure gas from the lower surface.

\subsection{Aerodynamic performance of the modified waverider}

The force coefficients of the lower surface for the two waveriders at $H=60 \mathrm{~km}$ are shown in Fig. 25. At the same angle of attack, the lift and drag coefficients of the modified waverider are lower 


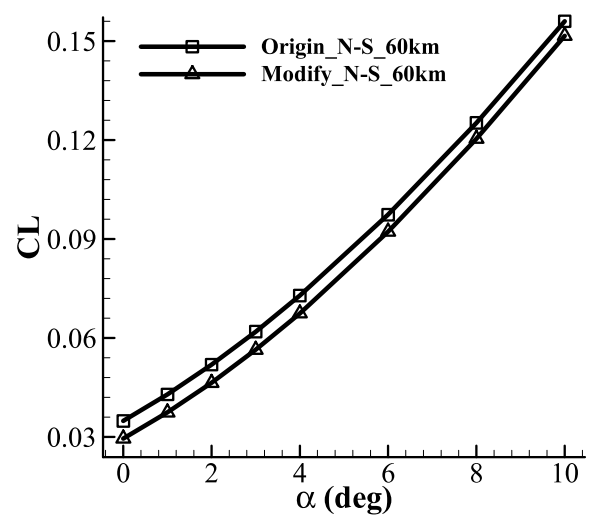

a) Lift coefficient

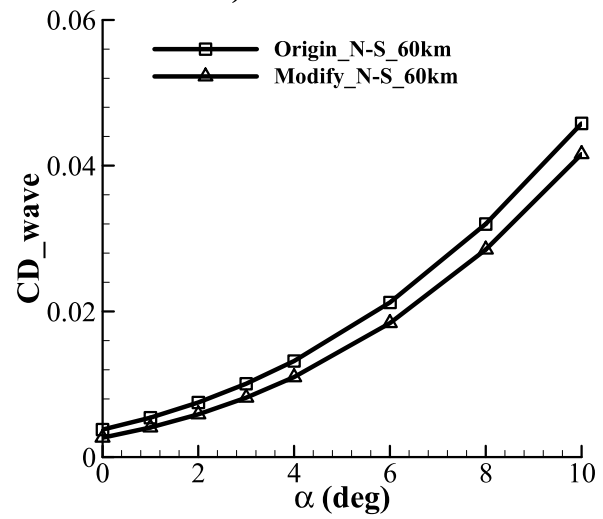

c) Wave drag coefficient

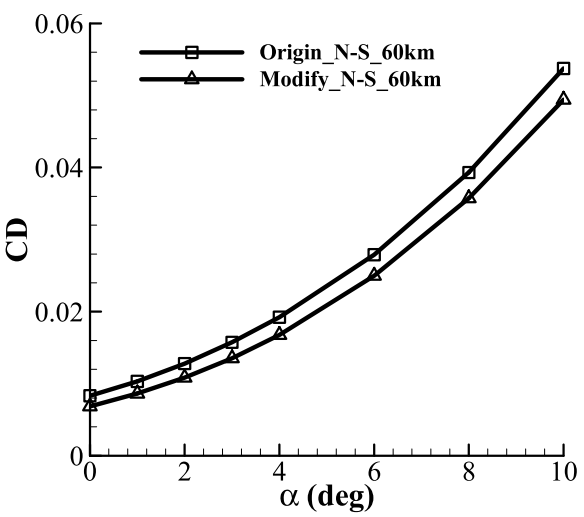

b) Drag coefficient

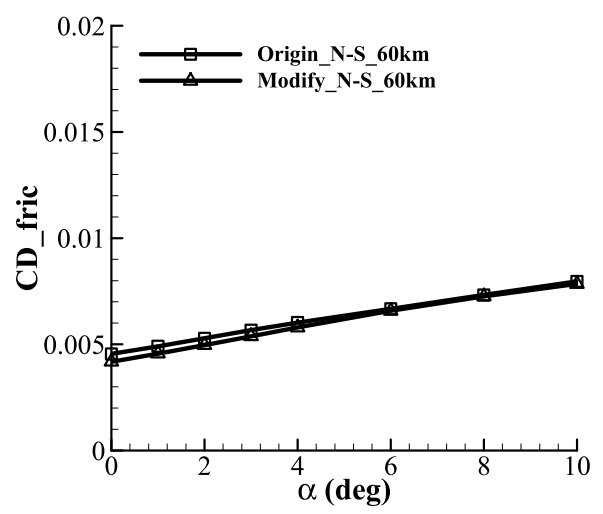

d) Friction drag coefficient

Fig. 25. Force coefficients of the lower surface for the two waveriders.

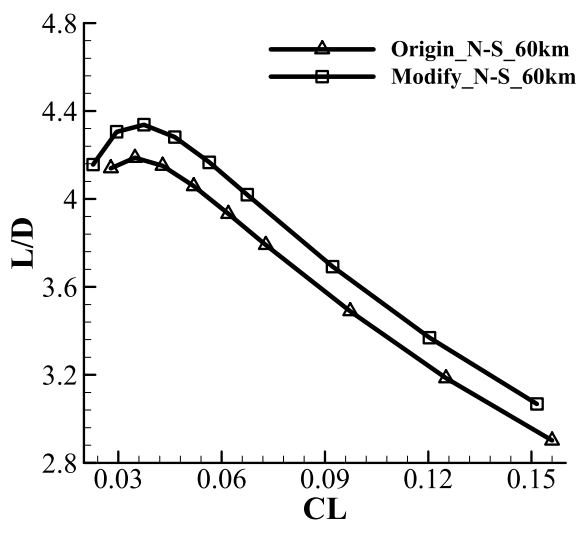

Fig. 26. $L / D$ of the lower surface for the two waveriders.

than those of the original waverider due to the lower pressure values. The decrease of drag is mainly owing to the wave drag, in that the difference of the friction drag between the two waveriders is minimal. Furthermore, the total $L / D$ of the lower surface are shown in Fig. 26 ( $\alpha:-1 \sim 10 \mathrm{deg}$ ). Compared to the original waverider, higher aerodynamic efficiency is obtained by the modified lower surface, with the maximum $L / D$ being improved from 4.18 to 4.34 .

In order to further inspect the reason for the improvement, the pressure distribution of the modified waverider at $\alpha=4.4 \mathrm{deg}$ and the original waverider at $\alpha=4 \mathrm{deg}$ is shown in Figs. 27-28. The different angle of attack is chosen to obtain an almost equal lift coefficient for the two waveriders $(C L=0.0735)$. According to

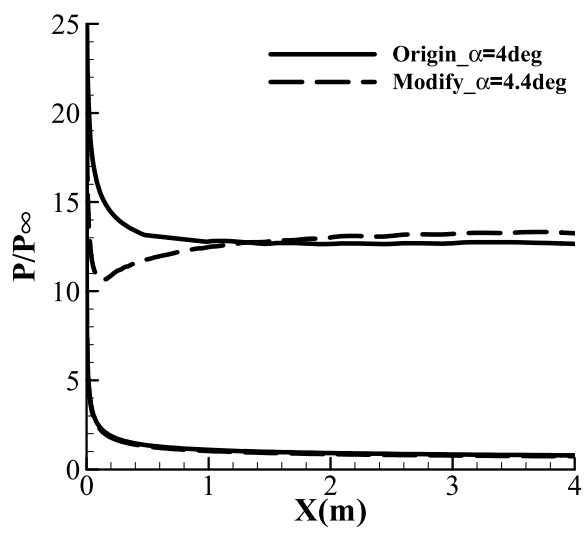

Fig. 27. Pressure distribution along the centerline.

the pressure distribution, the improvement of $L / D$ should mainly attribute to the pressure decrease near the leading edge, which reduces the wave drag by $7.0 \%$. As a result, the inviscid $L / D$ and total $L / D$ are improved by $6.35 \%$ and $4.34 \%$, respectively.

\subsection{Range of application}

A series of modified waveriders at different altitudes are generated according to the optimum values of $C_{\text {eff }}$, listed in Table 4 . Two of the modified waveriders are shown in Fig. 29. Different lower surfaces are obtained due to the different viscous interaction effects. 


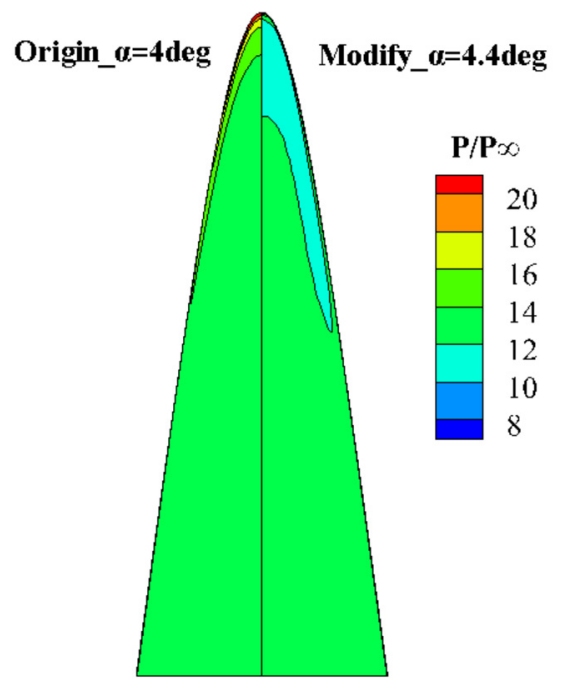

Fig. 28. Pressure contour of the lower surface.

\section{Table 4}

Optimum $C_{\text {eff }}$ at different conditions.

\begin{tabular}{llll}
\hline$M_{\infty}$ & $H$ & $\bar{V}^{\prime} \times 10^{-2}$ & $C_{\text {eff }}$ \\
\hline 15 & 40 & 0.476 & 0.395 \\
15 & 45 & 0.681 & 0.715 \\
15 & 50 & 0.945 & 0.954 \\
15 & 55 & 1.267 & 1.451 \\
15 & 60 & 1.707 & 2.332 \\
\hline
\end{tabular}

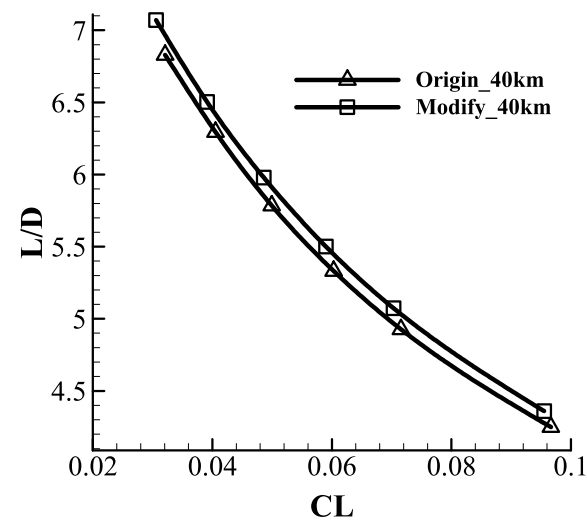

a) $H=40 \mathrm{~km}$

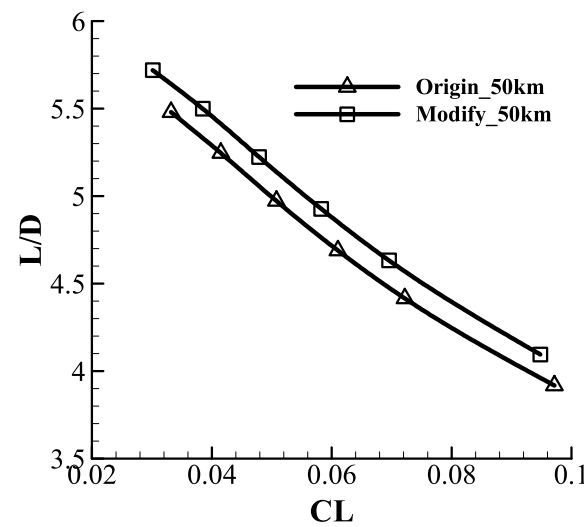

c) $H=50 \mathrm{~km}$

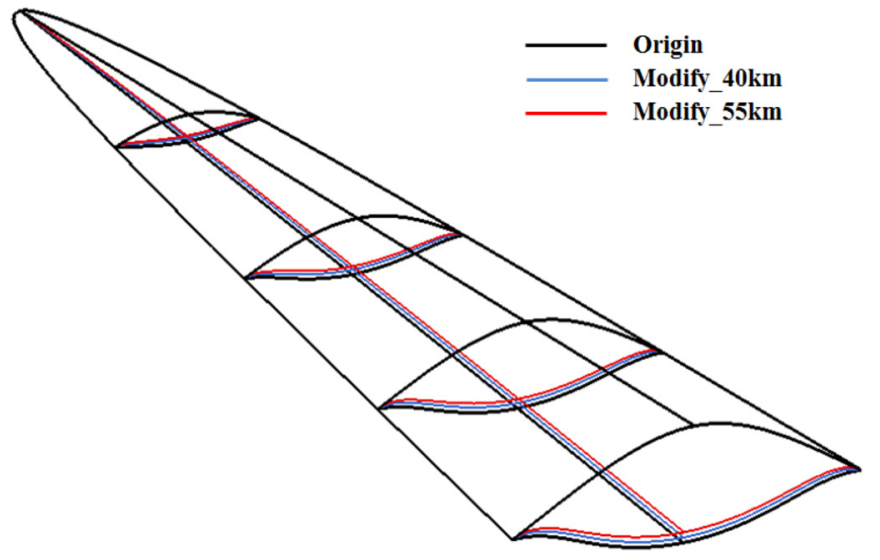

Fig. 29. Comparison of the original and modified waveriders at different design conditions.

Fig. 30 shows the comparison of $L / D$ between the original lower surface and the modified ones at different design conditions. Apparently, the modified waveriders have higher aerodynamic efficiency. Fig. 31 shows the relative improvement of $L / D$ as a function of $\bar{V}^{\prime}$ at the same lift coefficient (for example, $C L=0.0735$ ). It's found that the improvement is more evident as the viscous interaction effects become stronger. Therefore, the modification method is more valid at higher altitudes. At the altitudes above $60 \mathrm{~km}$, the rarefied flow phenomena will play a more and more important part on the aerodynamic characteristics of hypersonic vehicles, thus it's not studied for the moment.

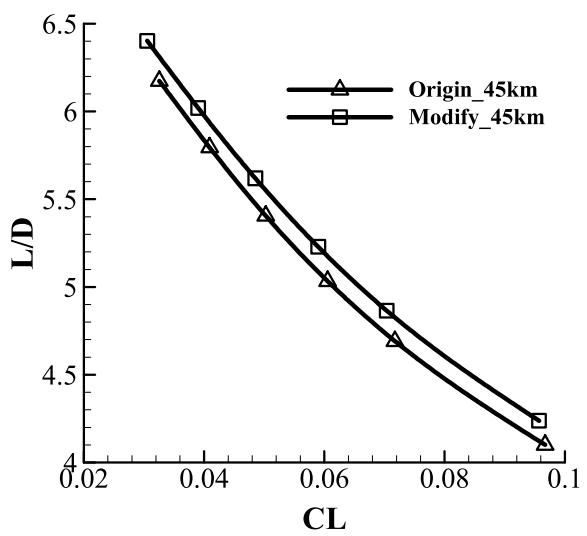

b) $H=45 \mathrm{~km}$

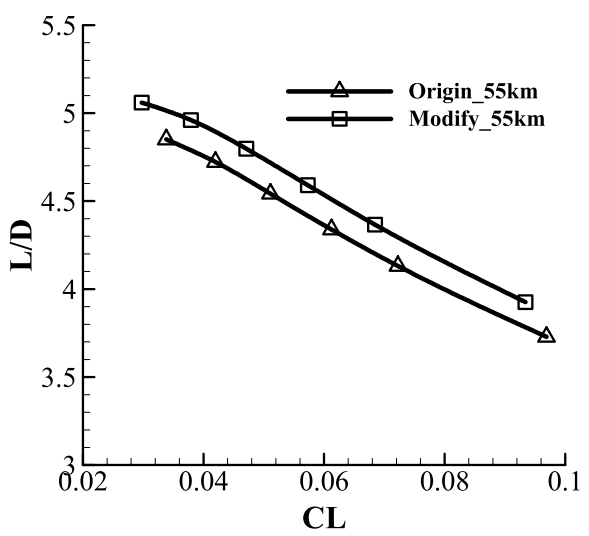

d) $H=55 \mathrm{~km}$

Fig. 30. Comparison of $L / D$ of the modified lower surface at different conditions, $\alpha=0-6$ deg. 


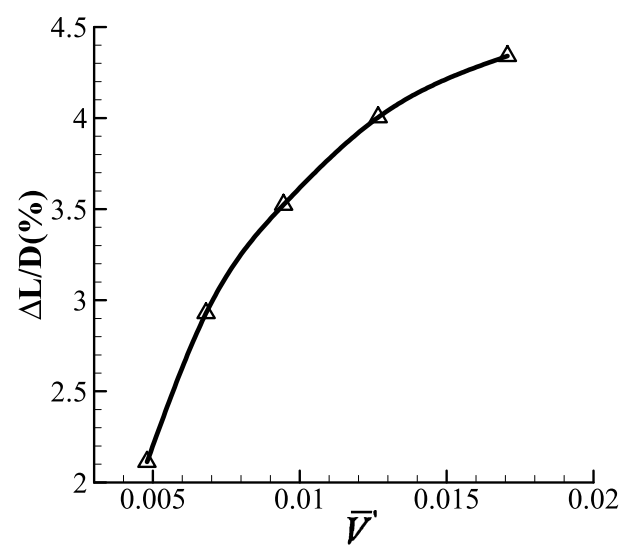

Fig. 31. Improvement of $L / D$ as a function of $\bar{V}^{\prime}, C L=0.0735$.

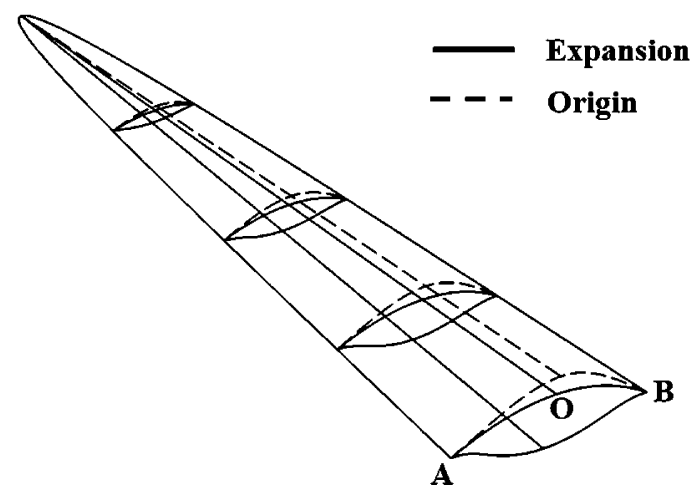

Fig. 32. Profiles of the original waverider and the waverider with an upper expansion surface.

\subsection{Compared to the waverider with an upper expansion surface}

When the upper freestream surface is taken into account, the comparison of $L / D$ is unfair for the original waverider because of its larger volume $\left(0.592 \mathrm{~m}^{3}\right)$. An optimization method to improve the $L / D$ of waverider used in the past researches is to make the upper surface an expansion one [8,37]. This method is adopted here to obtain a waverider with the same volume as the modified waverider $\left(0.468 \mathrm{~m}^{3}\right)$ in Fig. 21. The profile of the new waverider with an upper expansion surface is shown in Fig. 32. First, the centerline of the original upper freestream surface is deflected downward by $1.4 \mathrm{deg}$. Then a spline is generated on the base plane by

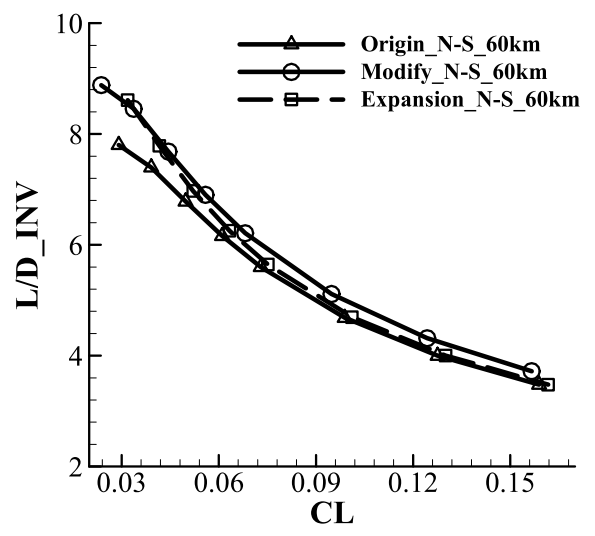

a) Inviscid $L / D$ connecting the three points A, O, and B. Finally, the expansion surface is generated according to the spline, the centerline, and the leading edge.

The values of $L / D$ of the three waveriders are shown in Fig. 33. When the lift coefficient is small at small angles of attack, the $L / D$ is improved by both optimization methods. However, as the increase in the lift coefficient, the $L / D$ of the waverider with an upper expansion surface gradually approaches that of the original waverider and becomes lower than that of the modified waverider evidently. Therefore, compared to the optimization method with an upper expansion surface, better aerodynamic efficiency can be achieved by the modified waverider designed in this paper.

The leading edge of real hypersonic waverider vehicles must be blunted according to the requirements of thermal protection. Therefore, the leading edge of the three waveriders described above is blunted with the bluntness radius being $10 \mathrm{~mm}$ and $20 \mathrm{~mm}$ by the adding material method suggested by Tincher [38]. The modified waverider with blunted leading edge is shown in Fig. 34. The values of $L / D$ are shown in Figs. 35 and 36. Apparently, the leading edge bluntness causes some loss of $L / D$. However, the trend comparison results are similar to those of waveriders with sharp leading edge. Therefore, higher aerodynamic efficiency of the modified waverider can also be kept when the leading edge is blunted.

\section{Conclusions}

A vorticity-based boundary layer displacement thickness determination method is developed in this paper, in combination with the tangent wedge/cone method. For the flat plate, a nearly linear relation between the effective shape determination coefficient $C_{\text {eff }}$ and the viscous interaction parameter $\sqrt{\bar{V}^{\prime}}$ is discovered, which can be used directly to calculate the effective shapes of general hypersonic thin bodies rapidly. For a more accurate evaluation of the displacement thickness, the optimum value of $C_{\text {eff }}$ should be found. Then the effective shapes obtained from this method are used to aid in analysis about the influence of strong viscous interaction and modify the lower surface of the original waverider.

The comparison of the aerodynamic performance of a viscous optimized cone-derived waverider is operated at the design Mach number between the Euler result and the $\mathrm{N}-\mathrm{S}$ results at $H=40 \mathrm{~km}, 50 \mathrm{~km}$, and $60 \mathrm{~km}$. As the altitude increases, the viscous interaction effects become stronger and the boundary layer displacement thickness becomes larger, thus deflecting the shock wave downward evidently. The influences of strong viscous interaction on the lift coefficient, drag coefficient and $L / D$ are also

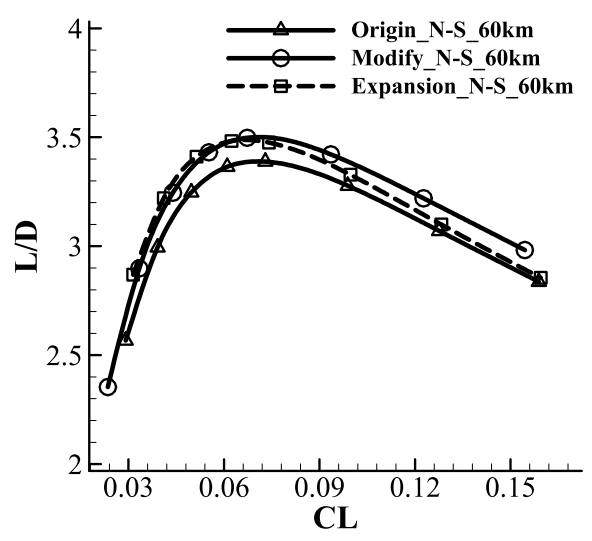

Fig. 33. $L / D$ of the three waveriders. 


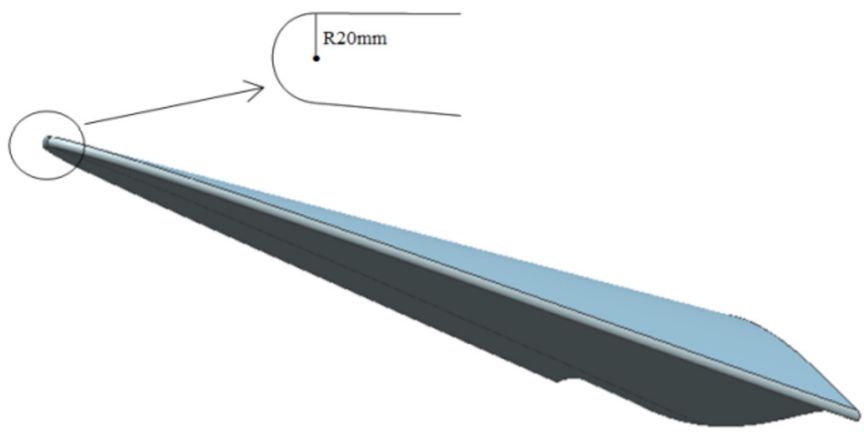

Fig. 34. Modified waverider with blunted leading edge.

analyzed in detail. As expected, the increase in friction drag is the main reason for the decrease in $L / D$. In addition, the increase in pressure on the upper surface also leads to the decrease in the inviscid $L / D$ (not including shear stresses).

In order to make the shock wave closer to the leading edge and alleviate the leakage of high pressure gas from the lower surface onto the upper surface, the original waverider is modified by deducting the corresponding boundary layer displacement thickness from the lower surface along the normal direction at $H=60 \mathrm{~km}$. It's found that the shock wave position around the lower surface of the modified waverider under the strong viscous interaction con- dition is very close to that of the inviscid basic flowfield, thus being closer to the leading edge than that around the original waverider. This means less leakage of high pressure gas. Different from expectations, such improvement of the shock wave position has little effect on the lift of the upper surface. However, an interesting discovery is that the modified lower surface exhibits higher aerodynamic efficiency than the original one, with the maximum $L / D$ being improved from 4.18 to 4.34 . Such improvement mainly attributes to the pressure decrease near the leading edge, which reduces the wave drag. For example, for the inviscid lift coefficient (not including the shear stresses) of 0.0735 , the wave drag of the modified lower surface is reduced by $7.0 \%$ compared to the original one. As a result, the inviscid $L / D$ and total $L / D$ are improved by $6.35 \%$ and $4.34 \%$, respectively. A series of modified waverider at different altitudes are also obtained. It's found that the improvement of $L / D$ is lowered as the viscous interaction effects become weaker.

The aerodynamic performance of the modified waverider is also compared to that of the waverider with an upper expansion surface with the same volume. The same improvement of $L / D$ by the upper expansion surface is obtained as the modified waverider at small angles of attack. However, at larger angles of attack, the modified waverider exhibits higher $L / D$. In addition, we should notice that the disadvantage of the present method is the reduction in the body volume. Therefore, the original waverider with the

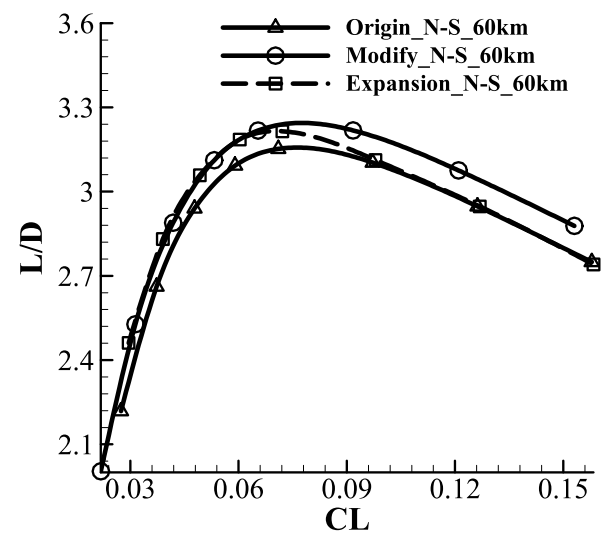

b) Total $L / D$

a) Inviscid $L / D$

dge $(R=10 \mathrm{~mm})$

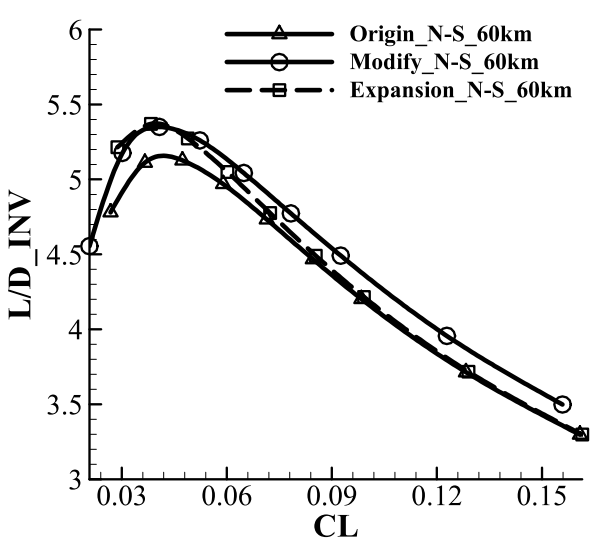

a) Inviscid $L / D$

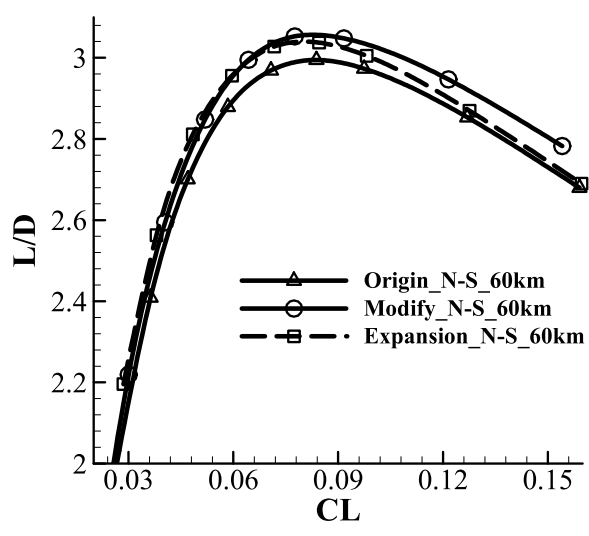

b) Total $L / D$

Fig. 36. $L / D$ of the three waveriders with blunted leading edge $(R=20 \mathrm{~mm})$. 
volume being slightly larger than the requirement should be chosen in engineering applications.

In summary, a vorticity-based boundary layer displacement thickness determination method is developed in this paper. The displacement thickness calculated by this method is used to modify the lower surface of the original waverider. The shock wave position around the modified lower surface under the strong viscous interaction condition is very close to that of the inviscid basic flowfield. What's more, the modified waverider exhibits higher aerodynamic efficiency than the original one due to the lower wave drag.

\section{Conflict of interest statement}

The authors declared that they have no conflicts of interest to this work.

\section{Acknowledgements}

The work was supported by the Strategic Priority Research Program (A) of Chinese Academy of Science (CAS) (XDA17030000) and National Natural Science Foundation of China (91216205 and 11272319). The computational work were carried out at the National Supercomputer Center in Tianjin, and the calculations were performed on TianHe-1(A).

\section{References}

[1] D. Kuchemann, The Aerodynamic Design of Aircraft, Pergamon Press, Oxford, 1978, pp. 448-510.

[2] T.R.F. Nonweiler, Aerodynamic problems of manned space vehicles, J. R. Aeronaut. Soc. 63 (1959) 521-528

[3] K.C. Moore, The Application of Known Flow Fields to the Design of Wings with Lifting Upper Surface at High Supersonic Speeds, R.A.E Technical Report, No. 65034, Feb. 1965.

[4] J.G. Jones, K.C. Moore, J. Pike, P.L. Roe, A method for designing lifting configurations for high supersonic speeds using axisymmetric flow fields, Arch. Appl. Mech. 37 (1) (1968) 56-72.

[5] B. Mangin, R. Benay, B. Chanetz, A. Chpoun, Optimization of viscous waveriders derived from axisymmetric power-law blunt body flows, J. Spacecr. Rockets 43 (5) (Sep.-Oct. 2006) 990-998, https://doi.org/10.2514/1.20079.

[6] B.S. Kim, M.L. Rasmussen, M.C. Jischke, Optimization of waverider configurations generated from axisymmetric conical flows, J. Spacecr. Rockets 20 (5) (Sep.-Oct. 1983) 461-469, https://doi.org/10.2514/3.25630.

[7] J.R. Liao, K.M. Isaac, J.B. Miles, B.J. Tsai, Navier-Stokes simulation for conederived waverider, AIAA J. 30 (6) (June 1992) 1521-1528, https://doi.org/ $10.2514 / 3.11096$

[8] K.G. Bowcutt, J.D. Anderson, D. Capriotti, Viscous optimized hypersonic waveriders, in: AIAA 25th Aerospace Sciences Meeting, Jan. 1987, AIAA Paper 87-0272.

[9] S. Corda, J.D. Anderson, Viscous optimized hypersonic waveriders designed from axisymmetric flowfields, in: AIAA 26th Aerospace Sciences Meeting, Jan. 1988, AIAA Paper 1988-0369.

[10] J.D. Anderson Jr., J. Chang, T.A. McLaughlin, Hypersonic waveriders: effects of chemically reacting flow and viscous interaction, in: 30th Aerospace Sciences Meeting and Exhibit, Jan. 1992, AIAA Paper 92-0302.

[11] H. Sobieczky, F.C. Dougherty, K. Jones, Hypersonic waverider design from given shock waves, in: Proceedings of the First International Hypersonic Waverider Symposium, University of Maryland, Oct. 17-19, 1990.

[12] N. Takashima, M.J. Lewis, Waverider configurations based on non-axisymmetric flow fields for engine-airframe integration, in: 32nd Aerospace Sciences Meeting and Exhibit, Jan. 1994, AIAA Paper 94-0380.

[13] P.E. Rodi, The osculating flowfield method of waverider geometry generation, in: 43rd AIAA Aerospace Sciences Meeting and Exhibit, Jan. 2005, AIAA Paper 2005-0511.
[14] P.E. Rodi, Vortex lift waverider configurations, in: 50th AIAA Aerospace Sciences Meeting including the New Horizons Forum and Aerospace Exposition, Jan. 2012, AIAA Paper 2012-1238.

[15] S. Corda, Star-body waveriders with multiple design Mach numbers, J. Spacecr. Rockets 46 (6) (Nov.-Dec. 2009) 1178-1185, https://doi.org/10.2514/1.43933.

[16] F. Ding, J. Liu, C. Shen, W. Huang, Novel approach for design of a waverider vehicle generated from axisymmetric supersonic flows past a pointed von Karman ogive, Aerosp. Sci. Technol. 42 (Feb. 2015) 297-308, https://doi.org/ 10.1016/j.ast.2015.01.025

[17] Y.B. Geng, H. Liu, H.H. Ding, F.M. Wang, Optimized design of waverider forebody derived from asymmetric near isentropic compression flow fields, J. Propuls. Technol. 27 (5) (Oct. 2006) 404-409 (in Chinese).

[18] F. Ding, J. Liu, C. Shen, W. Huang, An overview of research on waverider design methodology, Acta Astronaut. 140 (Aug. 2017) 190-205, https://doi.org/ 10.1016/j.actaastro.2017.08.027.

[19] N. Takashima, M.J. Lewis, Optimization of waverider-based hypersonic cruise vehicles with off-design considerations, J. Aircr. 36 (1) (Jan.-Feb. 1999) 235-245, https://doi.org/10.2514/2.2430.

[20] J.R. Maxwell, Shapeable hypersonic waverider entry vehicles, in: 53rd AIAA/SAE/ASEE Joint Propulsion Conference, July 2017, AIAA Paper 2017-4880.

[21] D.B. Johnson, R. Thomas, D. Manor, Stability and control analysis of a waverider TSTO second stage, in: AIAA/NAL-NASDA-ISAS 10th International Space Planes and Hypersonic Systems and Technologies Conference, April 2001, AIAA Paper 2001-1834.

[22] P.E. Rodi, G.J. Bennett, High lift-to-drag ratio waveriders for missions in the Martian atmosphere, in: 30th AIAA Applied Aerodynamics Conference, June 2012, AIAA Paper 2012-3221.

[23] H. Kato, J.C. Tannehill, Numerical calculation of viscous flow over hypersonic waveriders, in: 15th Applied Aerodynamics Conference, 1997, AIAA Paper 97-2292.

[24] N. Takashima, M.J. Lewis, Navier-Stokes computation of a viscous optimized waverider, J. Spacecr. Rockets 31 (3) (May-June 1994) 383-391, https://doi.org $10.2514 / 3.26450$.

[25] M.L. Rasmussen, R.T. Broadaway, Viscous effects on the performance of conederived waveriders, in: AIAA Atmospheric Flight Mechanics Conference, Aug. 1983, AIAA Paper 83-2084

[26] X. He, M.L. Rasmussen, Computational analysis of off-design waveriders, J. Aircr. 31 (2) (March-April 1994) 345-353, https://doi.org/10.2514/3.46493.

[27] J.D. Anderson Jr., Hypersonic and High-Temperature Gas Dynamics, 2nd ed., AIAA, Reston, VA, 2006.

[28] Y.W. Jiang, Numerical Solution of Navier-Stokes Equations on Generalized Mesh and Its Application, Ph.D. dissertation, Northwestern Polytechnical Univ., Xi'an, China, 2012 (in Chinese).

[29] M.S. Liou, Progress towards an improved CFD method-AUSM+, in: 12th Computational Fluid Dynamics Conference, AIAA Paper 95-1701.

[30] R.F. Chen, Z.J. Wang, Fast, block lower-upper symmetric Gauss-Seidel scheme for arbitrary grids, AIAA J. 38 (12) (Dec. 2000) 2238-2245, https://doi.org/ $10.2514 / 2.914$

[31] R.H. Hua, C.X. Zhao, Z.Y. Ye, Y.W. Jiang, Effect of elastic deformation on the trajectory of aerial separation, Aerosp. Sci. Technol. 45 (April 2015) 128-139, https://doi.org/10.1016/j.ast.2015.04.015.

[32] W.K. Lockman, S.L. Lawrence, J.W. Cleary, Flow over an all-body hypersonic aircraft: experiment and computation, J. Spacecr. Rockets 29 (1) (Jan.-Feb. 1992) 7-15, https://doi.org/10.2514/3.26308.

[33] U. Goldberg, O. Peroomian, P. Batten, S. Chakravarthy, The $k-\varepsilon-$ Rt turbulence closure, Eng. Appl. Comput. Fluid Mech. 3 (2) (2009) 175-183, https://doi.org/ 10.1080/19942060.2009.11015263.

[34] W. Liu, C.A. Zhang, H.Q. Han, F.M. Wang, Local piston theory with viscous correction and its application, AIAA J. 55 (3) (March 2017) 942-954, https:// doi.org/10.2514/1.J055207.

[35] J.D. Anderson Jr., Fundamentals of Aerodynamics, 4th ed., McGraw-Hill, New York, 2005.

[36] J.A. Nelder, R. Mead, A simplex method for function minimization, Comput. J. 7 (Jan. 1965) 308-313.

[37] Y.K. Wang, S.F. Yang, D.J. Zhang, X.Y. Deng, Design of waverider configuration with high lift-drag ratio, J. Aircr. 44 (1) (Jan.-Feb. 2007) 144-148, https:// doi.org/10.2514/1.22669.

[38] D.J. Tincher, D.W. Burnett, Hypersonic waverider test vehicle: a logical next step, J. Spacecr. Rockets 31 (3) (May-June 1994) 392-399, https://doi.org/ $10.2514 / 3.26451$ 